\title{
Network Effects in Corporate Governance
}

\author{
Sarath Sanga* \\ Northwestern University
}

August 12, 2019

\begin{abstract}
Most public companies incorporate in Delaware. Is this because they prefer its legal system or are they simply following a trend? Using the incorporation histories of over 22,000 public companies from 1930 to 2010, I show that firms are more influenced by changes in each other's decisions than by changes in the law. The analysis exploits an unexpected legal shock that increased Delaware's long-run share from 30 to 74 percent. I attribute most of this change to a cascading effect in which the decisions of past firms successively influence future cohorts. These decisions are also highly path dependent: In a counterfactual setting without switching costs, firms would be five times more likely to reincorporate in response to a given a legal change. I conclude that network effects dominate secular trends in corporate governance.
\end{abstract}

Keywords corporate governance, network effect, information cascade, path dependence

JEL G30, K22

*Author's email: sanga@northwestern.edu. I thank Roberta Romano, who made contributions to this paper and is primarily responsible for assembling the legal domicile data. I also thank Eric Talley, Holger Spamann, Steven Davidoff Solomon, Gabriel Rauterberg, Louis Kaplow, Christine Jolls, and seminar participants at University of Chicago, University of Michigan, Harvard University, University of Pennsylvania, Boston University, George Mason, Hitotsubashi University, Northwestern University, New York University, University of Toronto, UC Berkeley, and the NBER Summer Institute for helpful comments. This research was supported by the Northwestern University Pritzker School of Law Faculty Research Program. 


\section{Introduction}

American firms are free to incorporate in any of the fifty states or even abroad, yet most public companies choose Delaware. Why? There are two theories. The first is that firms choose Delaware because they value the intrinsic qualities of its corporate governance system, that is, its rules for resolving conflicts among shareholders, managers, and other corporate claimants. ${ }^{1}$ Some argue these rules maximize firm value and therefore appeal to shareholders. 2 Others argue they enable insiders to appropriate value and therefore appeal to unscrupulous managers $]^{3}$ While these explanations diverge on the predicted effects of a given legal change, they agree on the fundamental claim that governance decisions are driven by the rules themselves. Call this the "legal quality hypothesis."

The second theory is that firms choose Delaware because other firms choose Delaware. This theory is at odds with the first if managers simply follow the trend or adopt the standard corporate governance regime, regardless of its content 4 Yet this theory may also be consistent with the first. Even if firms only care about legal quality, firms may be influenced by each other's decisions because they interpret them as signals of legal quality. Over time, this can generate an information cascade in which firms ignore their private valuations over governance regimes and instead follow the trend 5 Further compounding this effect, a governance regime may become more valuable as more firms adopt it. For example, when a firm adopts the standard governance regime, it saves directors the burden of learning a new set of rules as they move from one firm to another, thus encouraging director mobility and information spillovers among firms in the network. It also grants the firm access to a global network of intermediary services that are well-versed in the standard, such as

\footnotetext{
${ }^{1}$ See, generally, Becht, Bolton and Röell $(2007)$.

${ }^{2}$ Winter (1977); Romano (1993); Easterbrook and Fischel (1996). A large literature studies the causes and effects of governance decisions, and specifically the incorporation decision. On causes, previous work has studied the influence of firm size (Dammann and Schündeln, 2009), the identity of investors (Broughman, Fried and Ibrahim, 2014), and the enactment of antitakeover statutes (Subramanian, 2002, Bebchuk and Cohen, 2003; Eldar and Magnolfi, 2017), though recent scholarship has questioned the salience of the latter on firm outcomes (Catan and Kahan, 2016, Cain, McKeon and Solomon, 2017). On effects, several papers have studied the effect of antitakeover statues on firm value (Cremers and Ferrell, 2014) as well as the effect of Delaware incorporation on firm value (Daines, 2001; Bhagat and Romano, 2002: Subramanian, 2004).

3 Cary (1974); Bebchuk (1992); Bebchuk and Hamdani (2002); Bebchuk, Cohen and Ferrell (2002).

${ }^{4}$ Zwiebel (1995) shows theoretically that relative compensation incentivizes managers to adopt industry standards because the ubiquity of a standard creates an accurate benchmark against which to evaluate managers; thus, managers not engaging in the standard take on uncompensated risk because their behavior is evaluated against a noisy benchmark.

${ }^{5}$ See, generally, Banerjee (1992); Bikhchandani, Hirshleifer and Welch (1992).
} 
international accounting firms, law firms, and investment banks. ${ }^{6}$ Moreover, the vastness of Delaware's network may itself be a source of legal quality, as firms can directly increase legal quality via litigation and lobbying. Frequent litigation can benefit non-litigant firms by resolving legal uncertainty, while lobbying efforts of one firm may similarly benefit nonlobbying firms.7 Scholars have long argued that these and other positive network externalities drive secular trends in corporate governance decisions, both in the U.S. and globally. 8 These explanations diverge as to the precise mechanism at work, yet they all yield one fundamental prediction: the average firm's decision affects the individual firm's decision. Call this the "network hypothesis."

In this paper, I examine the legal quality and network hypotheses in corporate governance. To the best of my knowledge, this study is the first to develop and estimate a model that disentangles network effects from legal quality effects. I conclude that network effects dominate.

The paper makes three contributions. The first contribution is theoretical. I propose a method to distinguish the contributions of network effects, legal quality effects, and path dependence in corporate governance decisions. The method is based on studying the transition between steady-state incorporation decisions following an unexpected change in the law. The intuition is as follows. Suppose a new firm's decision to incorporate depends on the quality of the law and the average behavior of all firms. Define the quality effect as the change in new firm behavior caused by a change in the law, and similarly define the network effect as the change in new firm behavior caused by a change in average firm behavior. Next suppose that a long period of legal calm is suddenly interrupted by a one-time legal shock at time $t=1$. The instantaneous reaction of new firms at $t=1$ is driven solely by the quality effect because, by assumption, the law has changed but average behavior has not.

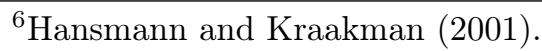

TThe Delaware legislature is particularly incentivized to respond to lobbying because incorporation revenue constitutes more than a quarter of its state budget. See Governor's Financial Overview, Fiscal Year 2018. Available at http://budget.delaware.gov/budget/fy2018/index.shtml. On consumption externalities generally, see Katz and Shapiro (1986).

${ }^{8}$ This debate has generated an extensive theoretical and comparative literature on the contribution of network versus quality effects in governance decisions. See, e.g., Klausner (1995); Kahan and Klausner (1997); Kamar (1998); Coffee (1998); Bebchuk and Roe (1999); Fisch|(1999); Gilson (2001); Hansmann and Kraakman (2001); Kahan and Kamar (2002); Daines (2002); Bar-Gill, Barzuza and Bebchuk (2006); Hadfield and Talley (2006); Romano (2006); Bratton and McCahery (2006); Talley (2015). The influence of peer firms is well documented in other corporate decision-making contexts, such as executive compensation (Bizjak, Lemmon and Naveen, 2008: Bizjak, Lemmon and Nguyen, 2011) and investment strategies (Grinblatt, Titman and Wermers, 1995; Nofsinger and Sias, 1999). The rise of standards is similarly documented in contract design (Kahan and Klausner, 1997; Sanga, 2014) and charter design (Romano and Sanga, 2017).
} 
By contrast, subsequent changes in new firm behavior in periods $t \geq 2$ are not driven by quality effects because, again by assumption, the law is not changing in subsequent periods. Subsequent changes are therefore responses to the initial change in average behavior. Further, by comparing the reactions of new firms with existing firms, I also obtain a measure of barriers to reincorporation, that is, the extent to which a firm's incorporation decisions are path dependent. Sections 2 and 3 formalize this intuition. Section 6.1 further shows that even if firms anticipate each other's current and future responses to the legal shock, it is still possible to identify a lower bound on the network effect so long as the shock itself is unexpected.

The second contribution is empirical. I produce estimates of network effects, legal quality effects, and state dependence in corporate governance decisions. These estimates come from an analysis of firms' long-run reactions to a collection of closely-related shocks to Delaware law occurring in 1985 and 1986. The first shock, occurring in January 1985, is arguably the most notorious 9 and unexpected corporate law decision of the 20th century: the case of Smith v. Van Gorkom. ${ }^{10}$ In Van Gorkom, the Delaware Supreme Court imposed personal monetary liability on the board of directors for breach of the duty of care, specifically for its failure to reach "an informed business judgment" when approving a sale of the company The immediate economic effect of the decision was a sudden increase in premiums for directors and officers insurance, even for firms not incorporated in Delaware. ${ }^{12}$ But its principal and enduring significance manifested the following year, on June 18, 1986, when the Delaware legislature responded by amending Delaware law. The new provision, codified in section 102(b)(7) ${ }^{13}$ enables a corporation ex ante to waive directors' personal monetary liability for breach of care, thereby avoiding outcomes like Van Gorkom ${ }^{14}$ Thus, for the first time, Delaware extended to directors the fundamental privilege of the corporate form: limited liability.

In the months between Van Gorkom and 102(b)(7), the Delaware Supreme Court also announced three significant decisions concerning takeover defenses: Revlon v. MacAndrews

\footnotetext{
${ }^{9}$ Fischel (1985) concludes that Van Gorkom was "surely one of the worst decisions in the history of corporate law."

${ }^{10} 488$ A.2d 858 (Del. 1985).

${ }^{11} \mathrm{Id}$. at 878 .

${ }^{12}$ See, e.g., Heron and Lewellen (1998).

${ }^{13}$ See Delaware Code Title 8, chapter $1, \S 102(\mathrm{~b})(7)$.

${ }^{14}$ Outside directors to public companies are now exposed to almost no out-of-pocket risk (Black, Cheffins and Klausner, 2005). Spamann (2016) offers a formal treatment on the tradeoffs of director liability.
} 
8 Forbes ${ }^{15}$ Unocal v. Mesa. ${ }^{16}$ and Moran v. Household International ${ }^{17}$ Of the three, Moran is arguably the most salient because it affirmed the poison pill, which enables a board to resist any hostile takeover ${ }^{18}$ Moran therefore reallocated significant control over the sale of the corporation from shareholders to the board 19 Prior literature has argued that Moran and 102(b)(7) were jointly responsible for making Delaware a more attractive corporate domicile.20

To study the long-run effects of these (nearly) coincident events, I examine the incorporation histories of over 22,000 U.S. public companies from 1930 to 2010. The incorporation histories were hand-collected and cover all firms in the Center for Research in Security Prices (CRSP) dataset on equity prices. These data enable us to study, for the first time, the evolution of incorporation decisions over the very long run.

Figures 1 and 2 show how incorporation decisions have evolved since 1930. Figure 1 graphs the number and share of non-Delaware public companies reincorporating to Delaware each year. Following the shocks of 1985 and 1986, the reincorporation rate spiked more than five-fold and achieved an historical maximum. Over 300 public companies moved to Delaware in two years. The reincorporation rate then returned to pre-shock levels. ${ }^{21}$ Figure 2 plots Delaware's share of both new and existing firms. These shares were roughly constant over the half-century leading up to 1986. After 1986, both shares discontinuously increased and asymptotically approached a new steady state.

\footnotetext{
${ }^{15} 506$ A.2d 173 (Del. 1986) (oral decision in 1985).

16493 A.2d 946 (Del. 1985).

${ }^{17} 500$ A.2d 1346 (Del. 1985).

${ }^{18}$ See Cremers and Ferrell (2014). Revlon introduced new constraints on the board's power to discriminate among hostile bidders, thus decreasing the scope of its discretion in takeovers. Unocal allowed a board to use a defensive and exclusionary self-tender to fend off a hostile tender offer.

${ }^{19}$ Moran's effect was also magnified by its timing, as the decision coincided with the peak of a takeover cycle. See Holmström and Kaplan (2001).

${ }^{20}$ See Netter and Poulsen (1989); Heron and Lewellen (1998). See also Romano (2006, pp.220-224). Many firms reincorporated to Delaware in the wake of these events (as described in detail below). Proxy statements filed with the Securities and Exchange Commission by firms reincorporating to Delaware during this time typically cite both 102(b)(7) and the poison pill as the key rationale (Netter and Poulsen, 1989). The literature has not come to a strong conclusion as to which of these events is most responsible for the reincorporation boom, and this paper does not take a strong position. Instead, this paper uses this unique collection of coincident shocks to study the long-run effects of a sudden and unexpected change in corporate law.

${ }^{21}$ Figure 1 reveals another smaller shock that occurred about 20 years prior. This reincorporation boom followed the 1967 overhaul of Delaware corporate law. See, generally, Corroon (1967); Arsht and Stapleton (1967); Dykstra (1967); Romano (1993). However, the empirical usefulness of this shock is limited because the legal overhaul was anticipated by the business and legal community. It therefore cannot be used to identify quality and network effects. Moreover, the data around this period are too sparse to permit meaningful statistical inference.
} 
Applying the model to the data, I obtain the main results of this paper: I estimate that the shocks of 1985 and 1986 increased Delaware's share of public companies by 44 percentage points (from 30 to 74 percent), and that network effects explain 70 percent of this increase. I also find strong evidence of path dependence in corporate governance decisions: Existing firms' immediate reactions were only one fifth the magnitude of new firms' reactions. Thus, in a counterfactual setting in which there are no barriers to reincorporation, firms would be five times more sensitive to legal changes.

The final contribution of this paper is an estimate of the value of a governance network. Specifically, I ask whether Delaware firms experienced abnormal returns over the years immediately following the legal shocks, when the size of the Delaware network experienced the largest gains. If a larger network adds value and investors accurately priced this, then we would not expect Delaware firms to experience abnormal returns. I find, however, that Delaware firms did experience abnormal returns. A zero-investment portfolio that bought Delaware firms and sold non-Delaware firms would have earned abnormal returns of 3.4 percent per year over the four years immediately following 102(b)(7). This result is consistent with the hypothesis that a larger governance network adds value. However, I interpret it with caution for two reasons. First, the abnormal returns could have been driven by investors' inability to price the legal change itself. I consider this alternative hypothesis in section 5.3 and find that the standard errors are too large to rule it out. Second, the abnormal returns are significant only after the standard four-factor adjustment from the performance attribution literature 22 The unconditional difference between Delaware and non-Delaware portfolios, while similar in magnitude, is not statistically significant at conventional levels. Using a simple power calculation, I show that given the volatility of equity prices, it is unlikely that an economically significant unconditional difference could be detected with these data.

I draw the following conclusions: The coincident extension of (1) limited liability for directors and (2) absolute discretion for directors in hostile takeovers was a watershed event. This event caused a convergence in legal domicile to Delaware. The legal change itself was only partly responsible. Most of the convergence was driven by a cascading effect in which governance decisions of existing firms successively influenced future cohorts. There is also suggestive evidence that governance networks exhibit positive network effects, i.e., that the benefit of incorporating in Delaware increases as more firms incorporate in Delaware.

Finally, it is worth considering the limitations of the results, the theoretical approach, and

\footnotetext{
${ }^{22}$ See Carhart (1997); Fama and French (1993).
} 
the empirical approach. At best, the results demonstrate that firms are strongly influenced by each other's decisions. The results do not rigorously distinguish among the myriad possible explanations for why firms are so influenced by each other's decisions ${ }^{23}$ Similarly, the results on abnormal returns suggest that convergence in governance systems itself adds value. The abnormal returns thus provide suggestive evidence toward one explanation for why firms are influenced by each other's decisions. They do not, however, provide any insight as to whether convergence to Delaware specifically (as opposed to any other jurisdiction) is efficient. They also provide no insight as to whether Delaware's specific laws are efficient.

As for the limits of the theoretical and empirical approach, the fundamental challenges associated with estimating peer effects ${ }^{24}$ are well known, and scholars have proposed several strategies to overcome these challenges 25 Perhaps the most straightforward approach is to rely on random assignment of groups. ${ }^{26}$ The approach taken in this paper is to exploit a key feature of the setting - that each year a cohort of new firms must make an initial governance decision - and then to posit conditions under which this feature can be used to identify the interdependence of incorporation decisions.

Relatedly, the empirical approach essentially treats the last 80 years as a long-run natural experiment in corporate law. This approach is motivated by the uniqueness of the magnitude of the reincorporation boom of 1986-1988 (figure 1) combined with the inference that the boom reflects a uniquely large and unexpected change in the Delaware legal system. Thus, though corporate law changes frequently, I infer from figure 1 that changes occurring before and after 1986 have had a relatively small impact on the average incorporation decision. (Section 6 investigates this in more detail.) A long-run approach also presents several advantages. A long-run approach explains secular trends in corporate governance decisions. All else equal, the results are therefore more likely to be externally valid. A long-run approach is also necessary to test the network hypothesis. The claim that "the average firm's decision affects the individual firm's decision" is a general equilibrium claim. To directly study it, we need a long time horizon over which to observe firms' reaction to other firms' decisions, as well as firms' reactions to those reactions, and so on. Further, many of the literature's proposed mechanisms, such as the feedback effect of a larger network on the quality of law,

\footnotetext{
${ }^{23}$ See footnote 8

${ }^{24}$ This paper uses the term "network effects" instead of "peer effects" because the large literature in corporate governance (footnote 8) uses the term "network effect" as a catch-all for any mechanism which results in the average firm's governance decision affecting the individual firm's governance decision.

${ }^{25}$ See, e.g., Manski (1993); Brock and Durlauf (2001); Gaviria and Raphael (2001); Graham (2008); Bramoullé, Djebbari and Fortin (2009).

${ }^{20}$ See, e.g., Sacerdote (2001).
} 
unfold over years, if not decades. In sum, while a long-run approach requires several strong assumptions, the approach of this paper is to leverage these assumptions to the fullest possible extent in order to provide both (1) a general theory to explain secular trends in corporate governance and (2) a specific theory to explain the ascendence of Delaware corporate law.

The rest of this paper is organized as follows. Section 2 presents the model. Section 3 uses the model to motivate the empirical strategy. Section 4 describes the data. Section 5 presents the results. Section 6 gives robustness checks and explores alternative theories. Specifically, 6.1 considers the case in which firms anticipate future firms' incorporation decisions, while 6.2 and 6.3 investigate the extent to which the data can validate the assumption that both the law and the composition of new firm types are stable before and after the shock. Section 6.4 considers several explanations based on theories of learning over time; it concludes that most of these explanations are consistent with this paper's principal result that firms are strongly influenced by each other's decisions. Section 7 concludes.

\section{A Model of Network Effects in Incorporation Decisions}

This section presents a model of incorporation decisions over time. In the model, each firm's decision depends on (1) the relative quality of Delaware law, (2) the firm's decision in the previous period, and (3) the average decision of all firms. I will refer to the contribution of each as, respectively, a quality effect, a state dependence effect, and a network effect.

\subsection{Setup}

A continuum of firms make incorporation decisions in discrete time. In each period, a new cohort is born and each firm in the cohort decides whether to incorporate in one of two possible states: Delaware or non-Delaware ${ }^{27}$ Existing firms also decide whether to remain in their current state or switch states by reincorporating. A firm survives to the next period with probability $\delta \in(0,1){ }^{28}$

\footnotetext{
${ }^{27}$ Prior literature has demonstrated that nearly all public companies incorporate either in their home state or in Delaware (Daines, 2002). The model parsimoniously captures this by reducing a firm's choice set to home (i.e., "non-Delaware") and Delaware.

${ }^{28}$ This presumes that Delaware and non-Delaware firms survive with the same probability. Empirically, this assumption seems valid. The survival rate over the entire sample period is 95.2 percent per year for Delaware firms and 95.5 percent per year for non-Delaware firms. The difference is -0.3 percent (s.e. 0.5). Allowing for heterogeneity in survival rates does not significantly alter the analysis. The main difference lies in accounting for changes in steady state. If the survival rate of Delaware firms is higher (lower) than non-Delaware firms, then, in steady state, the Delaware share of all firms will be higher (lower) than the
} 
A firm will choose Delaware if both (1) the actual quality of Delaware law and (2) the average behavior of other firms exceed certain firm-specific thresholds. A firm's quality threshold is determined as follows. In each period, $t$, firm $i$ draws $\widetilde{q}_{i t}$ from a distribution with c.d.f. $F(q)$. In its first period, the firm's quality threshold is $q_{i t}=\widetilde{q}_{i t}$. In subsequent periods, its threshold evolves according to

$$
q_{i t}= \begin{cases}q_{i t-1} & \text { if } \omega_{i t} \neq S \\ \widetilde{q}_{i t} & \text { if } \omega_{i t}=S\end{cases}
$$

where $\omega_{i t}$ is a firm-specific state of the world at time $t$ and

$$
\operatorname{Pr}\left(\omega_{i t}=S\right)=r
$$

The parameter $r \in(0,1]$ captures the probability that a firm experiences an idiosyncratic shock (the event $S$ ), such as merger, a physical move in headquarters, or any other change in the business model that would affect the costs and benefits of incorporating in Delaware. A firm's network threshold, $n_{i}$, is drawn once and for all in its first period from the c.d.f. $G(n)$. For convenience, assume that $n$ and $q$ are independently distributed 29

In its first period $(t=j)$, firm $i$ incorporates in Delaware if both legal quality and average behavior exceed $i$ 's firm-specific thresholds. That is, letting $X_{i j t}$ be an indicator equal to one if firm $i$ of cohort $j$ is incorporated in Delaware in period $t$,

$$
X_{i j t=j}=I\left(Q_{t}>q_{i t}\right) \times I\left(\bar{X}_{t-1}>n_{i}\right)
$$

where $I(\cdot)$ is the indicator function, $Q_{t}$ is the actual quality of Delaware law as of time $t$, and $\bar{X}_{t-1}$ is the Delaware share of firms as of time $t - 1 \longdiv { 3 0 }$ I assume that $Q_{t}$ and $\bar{X}_{t-1}$ are publicly known before firms make time- $t$ decisions.

In all subsequent periods $(t>j)$, firm $i$ sets

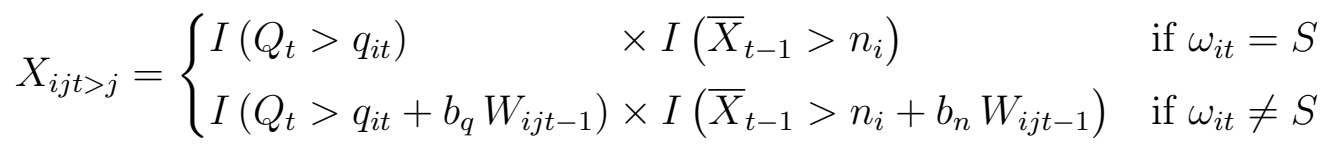

Delaware share of new firms. If survival rates are equal, then these shares are also equal in steady state. This equality simplifies the estimation of changes in steady state levels.

${ }^{29}$ Even if they are not independently distributed, the parameters of interest (appropriately reinterpreted) are still identified over particular values of $Q$ and $\bar{X}$. See below.

${ }^{30}$ This rules out forward-looking behavior. I return to this assumption in section 6.1 
where $W_{i j t} \equiv\left[1-X_{i j t}, X_{i j t}\right]^{\prime}, b_{q}=\left[b_{q}^{0},-b_{q}^{1}\right]$, and $b_{n}=\left[b_{n}^{0},-b_{n}^{1}\right]$. The vectors $b_{q}$ and $b_{n}$ parameterize the extent to which Delaware and non-Delaware firms' decisions are statedependent.

Definition 1. (State dependence) Non-Delaware firms' quality thresholds are state dependent if $b_{q}^{0}>0$. Non-Delaware firms' network thresholds are state-dependent if $b_{n}^{0}>0$. State dependence for Delaware firms' thresholds are similarly defined.

A firm's incorporation decision is state dependent if, after its initial decision, the firm becomes insensitive to small changes in legal quality and average behavior. This is modeled by positing that non-Delaware firms' quality and network thresholds increase by $b_{q}^{0}$ and $b_{n}^{0}$, while Delaware firm's thresholds decrease by $b_{q}^{1}$ and $b_{n}^{1}$. Thus, for example, a non-Delaware cohort- $j$ firm that was on the quality margin at the time of its initial decision $(t=j)$ would reincorporate in a subsequent period only if (1) quality subsequently increased by at least $b_{q}^{0}$ or (2) it experienced a firm-specific shock 31

Incorporation decisions are state dependent because there exist significant costs to reincorporating. These costs generate a "structural" state dependence, in the sense used by Heckman (1981), because a firm's current state has a causal effect on the relative prices of future states. That is, the costs of being a Delaware corporation in period $t$ are high as a consequence of being a non-Delaware corporation in period $t-1$. These costs may arise from actual outlays required to run a proxy campaign or update practices to comply with a new set of corporate duties. These costs may also arise from managers' implicit disincentives to deviate from past practice (Zwiebel, 1995).

A few notational points. A superscript plus or minus is sometimes used as a shorthand for plus or minus one (e.g., $t^{+} \equiv t+1$ ), $\Delta$ denotes changes in a variable, (e.g., $\Delta \bar{X}_{t}=\bar{X}_{t}-\bar{X}_{t-1}$ ) and an asterisk denotes steady-state quantities (e.g., $\left.\bar{X}^{*}\right)$. I will write $\bar{X}_{\cdot j t}$ to refer to the share of cohort- $j$ firms incorporated in Delaware as of time $t$. Similarly, $\bar{X}_{\text {.tt }}$ refers to the share of new (cohort- $t$ ) firms incorporating in Delaware at time $t$. Thus, replacing an index with a dot denotes taking an average over that index. Where there is no confusion, I write $\bar{X}_{t}$ instead of $\bar{X}_{. . t}$ to denote the share of all firms incorporating in Delaware as of time $t$.

\footnotetext{
${ }^{31}$ Note that the same firm-specific shock that leads to a firm making a new draw from $F(\cdot)$ also annihilates state dependence. This assumption is for convenience and is meant to capture the possibility that steady state reincorporation rates are not zero. (See below.) The estimation section will show that the main results do not depend on this particular approach to modeling state dependence and steady-state reincorporation.
} 


\subsection{Equilibrium}

Given a constant quality of law (i.e., some $s$ such that $Q_{t}=Q$ for all $t>s$ ), the steady state share of Delaware firms is

$$
\begin{aligned}
\bar{X}^{*} & =\lim _{t \rightarrow \infty} \bar{X}_{t} \\
& =F(Q) G\left(\bar{X}^{*}\right) .
\end{aligned}
$$

It is clear from equation 5 that a change in legal quality from $Q$ to $Q^{\prime}$ affects the steady state level of incorporation only if there exist firms with quality thresholds between $Q$ and $Q^{\prime}$. Otherwise, $F(Q)=F\left(Q^{\prime}\right)$ and so $\bar{X}^{*}$ does not change. This motivates the following definitions of quality and network effects.

Definition 2. (Quality effects) There exist legal quality effects over intervals of $Q$ for which $F(Q)$ is strictly increasing.

Definition 3. (Network effects) There exist network effects over intervals of $\bar{X}$ for which $G(\bar{X})$ is strictly increasing. There are no network effects if $G(0)=1$.

There may be several solutions to equation 5 . Figure 3 plots an example. For simplicity, it assumes that the law is constant and there is no state dependence $\left(Q_{t}=Q\right.$ for all $t$ and $\left.b_{q}=b_{n}=0\right)$. The network effect is positive when the product $F(Q) G(\bar{X})$ is above the 45-degree line, and negative when it is below. Steady state is achieved at points for which $F(Q) G(\bar{X})$ intersects the 45-degree line. There are three equilibria in figure 3 For high (low) initial values of $\bar{X}_{0}$, the high (low) equilibrium obtains. The middle equilibrium is a knife-edge case. Multiple equilibria are possible because of network effects. If there were no network effects, then $\bar{X}^{*}=F(Q) G(\bar{X})=F(Q)$ and each level of $Q$ would map to a unique steady state, regardless of the initial condition.

Figure 3 demonstrates how network effects generate a cascade over time. When the share of firms for whom the network threshold is met, $G(\bar{X})$, exceeds a critical level, $\bar{X} / F(Q)$, the marginal firm switching to Delaware induces the next marginal firm to switch to Delaware, which induces the next marginal firm to switch, and so on. This is indicated by the progression in Delaware's share from $\bar{X}_{0}$ to $\bar{X}_{1}$ to $\bar{X}_{2}$. When the share of firms for whom the network threshold is met falls below the critical level, the cascade proceeds in the opposite direction: the marginal firm leaves Delaware, which induces the next marginal firm to leave, and so on. Steady state obtains when the share of firms for whom the network threshold is met equals the critical level. 


\section{Estimation Strategy}

I next propose a method for estimating the contributions of quality effects, network effects, and state dependence. The method is based on studying the transition between steady states following a one-time change in the quality of law. I will therefore suppose throughout the rest of this paper that a system in steady state experiences a one-time, unexpected, positive shock to legal quality in the amount of $\Delta Q$ at time $t=1$.

\section{Assumption 1. (One-time quality shock)}

$$
\begin{aligned}
& \bar{X}_{t}=\bar{X}^{*} \\
& Q_{t}= \begin{cases}Q_{0} & \text { if } t<1 \\
Q_{0}+\Delta Q & \text { if } t<1\end{cases}
\end{aligned}
$$

Before giving formal definitions, figure 4 offers some intuition behind the method of distinguishing among legal quality, network, and state dependence effects. Figure 4 plots the evolution of $\bar{X}$ given different levels of legal quality and network effects. For simplicity, figure 4 a begins by assuming no state dependence. It then compares two cases: (1) a quality effect only and (2) both a quality and network effect. The immediate response (at $t=1)$ is the same for each case. This is because time 1 decisions depend on legal quality as of the current period $\left(Q_{1}\right)$ and the average incorporation decision as of the previous period $\left(\bar{X}_{0}\right)$. As of time 1 , only the former has changed. When there are no network effects, the new steady state obtains immediately: After time 1, there are no additional changes to average incorporation decisions. By contrast, when there are network effects, the immediate response is followed by an additional increase in incorporation rates at $t=2$, as firms react to the initial jump in incorporation rates from $\bar{X}_{0}$ to $\bar{X}_{1}$. This reaction is then further compounded over time as firms continue to respond to increases in $\bar{X}$ from the previous period. Thus, when there is no state dependence, the immediate response of new (or existing) firms can be used to measure the effect of legal quality, while subsequent increases can be used to measure the network effect.

Figure $4 \mathrm{~b}$ considers the effect of state dependence. It presumes both quality and network effects and then compares two cases: (1) state dependence in the quality threshold only (hollow circles and dashed line) and (2) state dependence in both the quality and network thresholds (solid circles and solid line). Two distinctions emerge. First, state dependence has no effect on new firms. This is by definition since new firms do not possess a previous 
state. For this reason, and because the network effect operates on lag (as explained above), the immediate responses of new firms are identical in all four cases considered in figures $4 \mathrm{a}$ and $4 \mathrm{~b}$. Thus, in the presence of state dependence, the immediate response of new firms (but not existing firms) isolates the legal quality effect. Second, existing firms' immediate responses depend on state dependence in $q$, but not on state dependence in $n$. Again, this is because average firm behavior has not changed as of the beginning of time 1 . Thus, state dependence in the quality threshold is identified by the difference in the immediate response of new versus existing firms. (As explained below, the estimation will also account for the change in steady-state reincorporation rates induced by the quality shock.) Also note that state dependence in $q$ and $n$ has no effect on steady state levels; it only slows down the transitions between steady states.

The measure of state dependence estimated in this paper is the quality threshold of nonDelaware firms $\left(b_{q}^{0}\right)$. This is arguably the most intuitive measure of state dependence in the context of a positive shock to Delaware law. It summarizes the barriers to immediately leaving non-Delaware jurisdictions. It is also the only state dependence parameter identified under assumption 1$]^{32}$ This is because measuring state dependence in quality thresholds for Delaware firms (i.e., barriers to leaving Delaware) would require a negative shock to Delaware law. Further, state dependence in network thresholds, $b_{n}$, is not identified. To see this, suppose $b_{n}$ were greater than zero. Existing firms' responses to other firms' behavior during post-shock periods would then be dampened, and this would tend to slow down the transition to a new steady state. Yet a slow transition could alternatively be explained by the (unobserved) shape of the distribution of network thresholds, $G(n)$.

Finally, to preview the results, figure 2 (also discussed above) plots the actual evolution of new and existing Delaware shares over the entire 81-year sample period. The shape of this plot closely matches the prediction from figure $4 \mathrm{~b}$, suggesting that all three effects (quality, network, and state dependence) are present. This figure is explained in more detail in section 4.

The remainder of this section formally defines measures of quality, network, and state dependence effects. The derivations of each are given in the appendix.

\footnotetext{
${ }^{32}$ More precisely, assumption 1 identifies a normalized measure of its magnitude.
} 


\subsection{Quality Effects}

Define the quality effect over the interval $\left[Q, Q^{\prime}\right]$ as

$$
\sigma\left(Q, Q^{\prime}\right)=\frac{F\left(Q^{\prime}\right)-F(Q)}{F(Q)}
$$

This is the rate of change in Delaware incorporation shares induced by a change in legal quality from $Q$ to $Q^{\prime}$, conditional on no network effects and no state dependence (i.e., $G(0)=$ 1 and $\left.b_{q}=b_{n}=0\right)$. This is identified in the first post-shock period over $\left[Q_{0}, Q_{0}+\Delta Q\right]$ because

$$
\sigma\left(Q_{0}, Q_{0}+\Delta Q\right)=\frac{\Delta \bar{X}_{\cdot 11}}{\bar{X}_{.00}},
$$

which is the rate of change of the Delaware share of new firms from $t=0$ to $t=1$. Intuitively, the immediate change in new firms's decisions isolates the quality effect because these decisions are not influenced by state dependence or network effects. The former is true because, by definition, new firms do not possess a state from the previous period. The latter is true because network effects only operate over changes in average behavior. Because we

begin in steady state, there are no recent changes in $\bar{X}$ as of $t=1$, when the first post-shock cohort makes initial decisions.

\subsection{Network Effects}

Define the network effect over the interval $\left[\bar{X}, \bar{X}^{\prime}\right]$ as

$$
\widetilde{\gamma}\left(\bar{X}, \bar{X}^{\prime}\right)=\frac{G\left(\bar{X}^{\prime}\right)-G(\bar{X})}{G(\bar{X})}
$$

This is the rate of change in Delaware incorporation shares induced solely by an increase in average behavior from $\bar{X}$ to $\bar{X}^{\prime}$. This is identified over the intervals $\left[\bar{X}_{t-1}, \bar{X}_{t}\right]$ for all post-shock periods $(t>1)$ because

$$
\widetilde{\gamma}\left(\bar{X}_{t-1}, \bar{X}_{t}\right)=\frac{\Delta \bar{X}_{t^{+} t^{+}}}{\bar{X}_{\cdot t t}},
$$

which is the rate of change in the Delaware share of new firms from $t$ to $t+1$. Intuitively, after the immediate change in the Delaware share of new firms, subsequent changes in new firm shares isolate the network effect because, by assumption, the actual quality of Delaware 
law is constant over post-shock periods. (Section 6.2 will return to this assumption by considering the case of secular trends in legal quality.)

To ease comparison with the quality effect, $\sigma$, I focus attention on the cumulative network effect on steady state rates,

$$
\begin{aligned}
\gamma & =\left(\prod_{t=1}^{\infty} 1+\widetilde{\gamma}\left(\bar{X}_{t-1}, \bar{X}_{t}\right)\right)-1 \\
& =\frac{\bar{X}^{*}-\bar{X}_{\cdot 11}}{\bar{X}_{\cdot 11}}
\end{aligned}
$$

where $\bar{X}^{*}$ is the new, post-shock steady state. This is the total network effect over all post-shock periods. Note that the analogous definition for the cumulative quality effect

$$
\left(\prod_{t=1}^{\infty} 1+\sigma\left(Q_{t-1}, Q_{t}\right)\right)-1=\sigma\left(Q_{0}, Q_{1}\right)
$$

is identical to the instantaneous quality effect. This highlights the assumption of the model that firms respond immediately to changes in legal quality, while the network effect unfolds over time as firms respond to changes in each other's behavior.

\subsection{State Dependence}

Finally, define the state dependence of non-Delaware firms' quality thresholds over the interval $\left[Q, Q^{\prime}\right]$ as

$$
\beta\left(Q, Q^{\prime}\right)=1-\frac{\left(F\left(Q^{\prime}-\widetilde{b}_{q}^{0}\right)-F(Q)\right) / F(Q)}{\sigma\left(Q, Q^{\prime}\right)}
$$

where $\widetilde{b}_{q}^{0}=\min \left\{b_{q}^{0}, Q^{\prime}-Q\right\}$. This is the fraction of the immediate increase in Delaware incorporation shares that is forgone by existing firms on account of state dependence in $q$. Put another way, the immediate effect on existing firms of increasing quality from $Q$ to $Q^{\prime}$ would be $\sigma$ in the absence of state dependence. However, because of state dependence, it is actually $\sigma(1-\beta)$. The denominator of equation 11 is the rate of change induced solely by legal quality ( $\sigma$, defined above), while the numerator is the same rate of change after accounting for state dependence. Thus, $\beta$ ranges from 0 to 1 , with higher $\beta$ indicating greater state dependence. $\beta=0$ implies no state dependence (or "frictionless" reincorporation), while $\beta=1$ implies that barriers to reincorporation are so large that existing firms do not react to the quality shock. 
State dependence of non-Delaware quality thresholds is identified in the first post-shock period over the interval $\left[Q_{0}, Q_{0}+\Delta Q\right]$ because

$$
\beta\left(Q_{0}, Q_{0}+\Delta Q\right)=\frac{\Delta \bar{X}_{\cdot 11}-p_{1}\left(1-\bar{X}_{\cdot 00}\right)}{\Delta \bar{X}_{\cdot 11}}+\xi
$$

where

$$
p_{1}=\operatorname{Pr}\left(X_{i j t=1}=1 \mid X_{i j t=0}=0\right)
$$

is the reincorporation rate for non-Delaware firms at time 1 and

$$
\xi=\frac{r}{1-r} \times \frac{1-\bar{X}_{.00}}{\Delta \bar{X}_{\cdot 11}} \times\left(\bar{X}_{\cdot 11}-p_{1}\right)
$$

is a remainder term to account for steady-state reincorporations due to random shocks.

To gain intuition in interpreting equation 12, suppose firms never experience a random shock $(r=0)$. In this case, the remainder term drops out and equation 12 is simply the (normalized) difference between the change in new firm behavior and the change in existing firm behavior. Thus, $\beta=0$ implies that reincorporation is frictionless because new and existing firms react identically to quality shocks. In this way, $\beta>0$ measures the extent to which existing firms' actual responses fall short of the theoretical frictionless rate.

The remainder term, $\xi$, accounts for the fact that firms experience random shocks even in steady state, and so some firms will have randomly reincorporated in the year of the Delaware quality shock. This is a second-order effect when the probability of a random shock is small. Further, as a third-order effect, this random reincorporation rate will itself have increased as a result of the quality shock. One way of interpreting this increase is that it accounts for the possibility that the effect of a legal change manifests several periods after the law changes. This could occur if, for example, a legal change would benefit firms that experience a particular event, such as a merger. In such cases, we would expect the legal change to induce some firms to reincorporate immediately, while others reincorporate years later when the event is imminent. If these second- and third-order effects were ignored, then estimates of $\beta$ would be downwardly-biased toward a finding of no state dependence. In practice, the steady-state level of reincorporation is low and so the estimates of $\xi$ are moderate (approximately 15 percent of the magnitude of $\beta$ ). Thus, the general result (that there are significant barriers to reincorporation) is not an artifact of the particular way in which the model accounts for these second- and third-order effects; even ignoring them completely would only modestly bias the estimates of state dependence. 


\section{Data}

\subsection{Data Collection}

The population of interest is all companies that have ever been included in the CRSP database of U.S. stock prices from January 1, 1930 through December 31, 2010. The CRSP database includes all companies that issued a security with primary listing on NYSE, NYSE American (previously known as the American Stock Exchange, or AMEX), and NASDAQ.33 The coverage begins in December 1925 for NYSE, July 1962 for AMEX, and December 1972 for NASDAQ. A firm enters the CRSP sample when it is listed on at least one of these exchanges; it exits the sample when it is no longer listed on any of these exchanges. I define a firm as "new" during the calendar year of its first observation on CRSP.

The incorporation status was obtained for over 99 percent of corporations in CRSP. The data were hand-collected from several digital and physical resources. These include databases maintained by the Securities and Exchange Commission, Thomson Reuters, Lexis, and Moody's. A limitation of the SEC's online EDGAR database is that the incorporation status listed on the header file is often inaccurate, particularly for firms that reincorporate. For this reason, incorporation data were not obtained from the header, but instead from 10-K, S-1, S-4, proxy statements, and other filings in which the corporate histories are often recounted, and to which the corporate charter and any amendments are sometimes attached. Another limitation of EDGAR is that its coverage of SEC filings begins in 1996. Data for earlier years come from online databases maintained by Thompson Reuters and Lexis, which includes coverage of SEC filings for some companies beginning in the 1980s. Hardcopies of Moody's issuance volumes were also consulted. Finally, for all other companies, incorporation histories were obtained by consulting microfiche of SEC filings available at the New York Public Library.

\subsection{Summary Statistics}

Table 1 presents summary statistics. The main sample includes 22,355 firms from 1930 to 2010. There are 272,948 firm-year observations (approximately 12 years per firm). Delaware is the leader in corporate charters by a large margin. Half of all public corporations have

\footnotetext{
${ }^{33} \mathrm{CRSP}$ also includes coverage for NYSE Arca and "other". I exclude Arca firms because coverage begins in March 2006, well after the legal shock. CRSP does not identify the exchange for "other" firms; these firms account for only about 1 percent of firm-year observations.
} 
been incorporated in Delaware at some time during their history as a public company. The next closest is California at 7 percent, followed by New York at 6 percent, Nevada at 3 percent, and Florida at 3 percent. About 6 percent of all public corporations reincorporated to Delaware after going public. Less than 1 percent of all public corporations left Delaware for another jurisdiction. Among all corporations, 15 percent were first listed on NYSE, 12 percent on AMEX, and 73 percent on NASDAQ.

Figure1 1 graphs the number and share of non-Delaware firms reincorporating to Delaware each year. During the 55 years leading up to 102(b)(7), an average of 8 firms reincorporated to Delaware each year. In 1987, the year following the passage of 102(b)(7), 190 firms reincorporated to Delaware. The rate of reincorporation spiked from less than 1 percent to more than 5 percent per year. Figure 1 also reveals a smaller yet significant reincorporation boom about 20 years prior 34

Figure 2 graphs Delaware's share of public corporations over time. It includes the share of all firms (the solid line) as well as the share of new firms (hollow circles). The two breaks at 1963 and 1973 indicate the years that AMEX and NASDAQ firms entered the sample. Over the half-century leading up to 102(b)(7), there was little trend in the share of new firms and the share of all firms. The share of all firms was 32 percent in 1930 and 34 percent in 1985. Between these years, however, it reached as high as 39.6 percent. Much of this variation can be attributed to the addition of AMEX and NASDAQ. New firms constitute about 5 percent of the total sample in any given year. After the passage of 102(b)(7), the share of new and existing firms increased sharply. By 2010, the share of all firms was 58 percent. The share of new firms grew even faster, and exceeded the share of all firms in every post-1986 year. On average, new firm shares exceed existing firm shares by about 8 percentage points.

\section{$5 \quad$ Network Effects in Incorporation Decisions}

The evolution of Delaware's share of new and existing firms (figure 22) closely matches the simulation in figure $4 \mathrm{~b}$, suggesting that incorporation decisions exhibit network effects $(\gamma)$, quality effects $(\sigma)$, and state dependence $(\beta)$. This section presents estimates of each. It also presents suggestive evidence that Delaware firms enjoyed abnormal returns in the years immediately following the quality shocks of 1985 and 1986.

\footnotetext{
${ }^{34}$ See footnote 21 .
} 


\subsection{Network and Quality Effects}

To measure network and quality effects, I use the sample of new firms to estimate variations of the following model of incorporation decisions

$$
X_{i t t}=f_{0}(t) \times I(t<1)+f_{1}(t) \times I(t \geq 1)+u_{i t t}
$$

where $X_{i t t}$ is an indicator that firm $i$ from cohort $t$ incorporated in Delaware at time $t, f_{0}(t)$ and $f_{1}(t)$ are separate pre- and post-shock time trends, and $u$ is an error term. The time variable, $t$, has been redefined so that $t=1$ is the year of the shock (i.e., $t=$ year -1985$)$. As a baseline, I specify the pre-trend with a constant,

$$
f_{0}(t)=c
$$

I also adopt linear and quadratic forms. Because the post-trend must account for an asymptote to the new steady state, I adopt the simple logistic form,

$$
f_{1}(t)=\frac{L}{1+e^{-k(t-a)}}
$$

where $a, k$, and $L$, are an intercept, gradient, and scaling parameter, respectively. ${ }^{35}$ Note $f_{1}(t)$ approaches $L$ as $t$ increases arbitrarily, while $k$ captures the rate of this approach. The estimate of the quality effect is then the instantaneous change in new firm decisions at $t=0$,

$$
\widehat{\sigma}=\frac{\widehat{f}_{1}(1)-\widehat{f}_{0}(1)}{\widehat{f}_{0}(1)}
$$

while the estimate of the network effect is the subsequent change to steady state

$$
\widehat{\gamma}=\frac{\widehat{L}-\widehat{f}_{1}(1)}{\widehat{f_{0}}(1)}
$$

\footnotetext{
${ }^{35}$ For robustness, I test for a trend break in Delaware's share of all firms at 1986 using a simplified, reduced-form specification. I also test for trend breaks in every year from 1960 to 2000 . Specifically, for each year, I regress $\bar{X}_{t}$ on separate pre and post linear trends using the sample of firms from 10 years before and after that year. Thus, for example, to estimate the discontinuity at 1990, I use the 1980-1999 sample to estimate equation 15 , setting $f_{0}(t)=c_{1}+c_{2} t, f_{1}(t)=c_{3}+c_{4} t$, and $t=$ year -1989 . The discontinuity is $f_{1}(1)-f_{0}(1)$. This produced 41 estimates, one for each year from 1960 to 2000 . Of these, the three years with the largest discontinuity (in absolute value) are the three years immediately following the shock: 1986, 1987, and 1988. Respectively, these estimates are 0.06 (s.e. 0.01) 0.07 (s.e. 0.01), and 0.06 (s.e. 0.02).
} 
Table 2 presents the main results. The estimates come from fitting the new firm data to equation 15 using nonlinear least squares and the delta method for inference. Standard errors are clustered by year. Each column presents estimates obtained using different time windows and pre-shock time trends. Columns 1-3 use the 50-year window surrounding the shock (1960-2010). Column 1 estimates the pre-trend with a constant. This is the baseline specification because a constant pre-trend follows immediately from assumption 1 . (I investigate the validity of this assumption in section 6.2.) Using the baseline specification, the estimated pre-shock steady state $\left(\bar{X}_{0}\right)$ is 0.30 and the estimated post-shock steady state $\left(\bar{X}^{*}\right)$ is 0.74 . The estimated network effect is 1.05 (s.e. 0.21 ) and the legal quality effect is 0.45 (s.e. 0.08). Interpreted literally, this means that the legal shock increased Delaware's long-run share of firms by 150 percent (from 0.30 to 0.74), and that network effects are responsible for 70 percent of this change 36 The estimates using linear and quadratic pretrends are comparable.

The last two columns use a linear pre-shock trend and restrict the sample to smaller windows around the shock. Column 4 restricts the sample to the 20 -year window surrounding the shock, while column 5 restricts it to the 12-year window. The fraction of the total change attributable to network effects is 0.55 (s.e. 0.06) for the 20-year window and 0.71 (s.e. 0.24 ) for the 12-year window. Figure 5 graphically presents the parametric fits from columns 3, 4, and 5 .

Restricting the estimation window affects the interpretation of the results. Restricting the pre-shock sample decreases the precision of the estimates of the pre-shock steady state. However, the advantage is that it also restricts the period over which the steady-state assumption must hold, that is, the period over which the law is constant and firm cohorts are comparable. Limiting the pre-shock sample thus mitigates the potential omitted variables problem inherent in cross-cohort comparisons.

Restricting the post-shock sample similarly yields less precise estimates of quality and particularly of network effects, as the latter requires estimation of an asymptote. It also changes the interpretation of the results. There are several reasons. First, as in the preshock restriction, it excludes cohorts far from the time of the shock and thus further mitigates omitted variables biases associated with cross-cohort comparisons. Second, it mitigates the extent to which the network effect estimate is contaminated by changes in legal quality that are unrelated to the shock and, importantly, also unrelated to changes in the composition and size of the Delaware network. Finally, it changes the interpretation of the network

\footnotetext{
${ }^{36} 150=100 \times(0.45+1.05)$ and $70=100 \times 1.05 /(1.05+0.45)$.
} 
effect. If the network of Delaware firms affects legal quality (via consumption externalities such as litigation and lobbying), then a narrower window would tend to exclude such longrun feedback effects. This could explain why I obtain smaller estimates of network effects for narrower time windows. Alternatively, the smaller estimates could be driven by the unobserved shape of the network threshold distribution.

It should be noted that a component of these estimates is predictive. In particular, the cumulative network effect relies on estimates of the new steady state, which is inferred from new firm behavior. To get a sense of how much of the cumulative effect is predictive, note that the predicted new steady state is 0.74 , whereas the actual Delaware share of all public corporations was about 0.58 as of 2010. Using the estimates from table 2 column 1 , the contribution of network effects to the total change in Delaware's share as of 2010 is therefore 0.57. 37 By comparison, the predicted long-run contribution of network effects is 0.70 (from column 1). Even still, virtually all of the network effect has already manifested in new firm behavior (see figure 5). In this way, the estimate of the long-run network effect, while predictive in nature, does not rely on an extrapolation of a trend in new firm behavior. Rather, it is the long-run effect on average firm behavior that will obtain if the law and the distribution of firm types remain constant.

\subsection{State Dependence}

I next estimate state dependence in governance decisions. To do this, I use the sample of non-Delaware firms $\left(X_{i j t^{-}}=0\right)$ to estimate the following model of reincorporation rates during the pre- and immediate post-shock periods:

$$
p_{i j t}=r \cdot \bar{X}_{\cdot t t} \cdot I(\leq 0)+p_{1} \cdot I(t=1)+v_{i t}
$$

where $p_{i j t}$ is an indicator equal to one if firm $i$ of cohort $j<t$ reincorporated to Delaware in period $t$ and $v$ is an error term. Recall that $r$ is the probability of a firm-specific shock. The first term of equation 20 is the form of the pre-shock steady state reincorporation rate implied by the model, the derivation of which is straightforward and given in the appendix. The second term is a separate, non-parametric measure of the reincorporation rate during the immediate post-shock period. I use the resulting estimates, $\widehat{r}$ and $\widehat{p}_{1}$, to produce an

estimate of state dependence, $\widehat{\beta}$ (see equation 12 . Note this also requires estimates of $\widehat{\bar{X}}_{.00}$

\footnotetext{
${ }^{37}$ Letting $\bar{X}_{2010}$ denote Delaware's share as of 2010, this is $\left(\bar{X}_{2010}-\bar{X}_{\cdot 11}\right) /\left(\bar{X}_{2010}-\bar{X}_{0}\right)=(0.58-$ $0.42) /(0.58-0.30)=0.57$.
} 
and $\widehat{\bar{X}}_{\cdot 11}$, which come from results of the previous regression (equation 15 ).

One problem with estimating existing firms' immediate responses $\left(p_{1}\right)$ is that it may not have been feasible for some firms to reincorporate in the first post-shock period. There are several reasons. First, 102(b)(7) was enacted in the middle of the year (June 1986). Second, and relatedly, reincorporation decisions are made via proposals at shareholder meetings, which typically occur only once per year. Further, new proposals require lead time in order to organize proxies and gather shareholder support. Thus, the "instantaneous" reaction (i.e., the component that is independent of changes in average behavior) likely occurred over the first two or perhaps even three years. Roughly, figure 1 suggests that the 3-year hypothesis may be accurate 38

To address this, I coarsen the time variable when producing estimates of state dependence. As a baseline, I take the coarsened time, $t^{\prime}$, to be 3 -year groups of $t$, so $t=-2,-1,0$ corresponds to $t^{\prime}=0, t=1,2,3$ corresponds to $t^{\prime}=1$, and so on. $X_{i j t^{\prime}}$ and $R_{i j t^{\prime}}$ are similarly coarsened ${ }^{39}$ The estimates of $\beta$ come from jointly fitting equations 15 and 20 to coarsened data using nonlinear least squares and the delta method for inference. Standard errors are clustered by the coarsened year.

Table 3 presents the results. Each of the five columns correspond to the models from table 2. The first row gives estimates of $\beta$, which are all about 0.8. Interpreted literally, this means that the immediate response of existing firms was 80 percent smaller than it would have been in the absence of state dependence. The second row gives estimates of the lower bound on state dependence, $\beta-\xi$, which is obtained by ignoring the second- and thirdorder effects of the legal shock on steady-state reincorporation rates (as explained in section 3.3). These estimates are roughly 15 percent smaller than the unbiased estimates. The pre-shock, steady-state reincorporation rate $\left(p_{0}\right)$ ranges from 0.006 to 0.008 (6 to 8 per 1000 non-Delaware firms per year). The immediate post-shock rate $\left(p_{1}\right)$ was 3 to 4 times greater. For reference, table 3 also presents estimates of $\bar{X}_{0}, \bar{X}_{.11}$, and $\bar{X}^{*}$ using the coarsened data. These are comparable to the same estimates obtained with non-coarsened data (table 2).

The results suggest that public companies face significant barriers to reincorporation. Because of these barriers, pre-IPO companies are approximately five times more sensitive to legal changes than post-IPO companies.

\footnotetext{
${ }^{38}$ In the decade leading up to 1986 , reincorporation rates were generally less than 1 percent. The rates in 1986, 87, and 88 were 1.3, 5.1, and 3.3, respectively. The rates in 1989, 90, and 91 were 1.5, 0.8, and 1.0 percent, respectively.

${ }^{39}$ Specifically, $X_{i j t^{\prime}=1}=X_{i j t=3}$ (if $X_{i j t=3}$ exists) or $X_{i j t=2}$ (if firm $i$ exited in $t=3$ ) or $X_{i j t=1}$ (if firm $i$ exited in $t=2$ ). Similarly, $R_{i j t^{\prime}=1}=1$ if $X_{i j t^{\prime}=0}=0$ and either $X_{i j t=1}=1$ or $X_{i j t=2}=1$ or $X_{i j t=3}=1$.
} 


\subsection{Network Value}

I next examine the relationship between the growth in Delaware's network and firm value. The total return of Delaware corporations over the first four years after the passage of 102(b)(7) was 22.4 percent, or 5.2 percent per annum. Over the same period, the total return of non-Delaware corporations was 12.6 percent, or 3.0 percent per annum. To determine the source of this difference, as well as its statistical significance, I regress the average monthly returns of several portfolios on the standard four controls from the performance attribution literature 40 Specifically, I estimate

$$
R_{t}=\alpha+\pi_{1} \mathrm{MKTRF}_{t}+\pi_{2} \mathrm{SMB}_{t}+\pi_{3} \mathrm{HML}_{t}+\pi_{4} \mathrm{UMD}_{t}+u_{t}
$$

where $R_{t}$ is the return of the asset in time $t$, and the right hand side variables are the returns of four zero-investment portfolios designed to control for (1) market exposure or "beta," which is the market return minus the risk-free rate (MKTRF), (2) firm size, which is the returns of a small firm portfolio minus a big firm portfolio (SMB), (3) book-to-market ratio or "value," which is the returns of a high-value portfolio minus low-value portfolio (HML), and (4) immediate past returns or "momentum" (UMD) ${ }^{11}$ The constant term, "alpha," is the excess return.

Table 4 presents four-factor regressions for the difference between Delaware and nonDelaware firms for various portfolio constructions. This difference corresponds to a zeroinvestment, value-weighted portfolio that buys Delaware firms and sells short non-Delaware firms. All regressions are performed over a time horizon of four years ${ }^{42}$ The first row includes all firms. If a firm reincorporates, then it is reassigned to its new domicile in the month after its reincorporation. 43 The abnormal monthly return is 28 basis points (3.4 percent annualized) and statistically significant (s.e. 11). The returns are roughly similar for a portfolio that drops firms as soon as they reincorporate ("Reincorporations excluded"), for

\footnotetext{
${ }^{40}$ See Fama and French (1993) and Carhart (1997). I do not take a position on the merits of this model or its ability to capture the true risk of a portfolio. Rather, following Gompers, Ishii and Metrick (2003) and others, I adopt this model to attribute differences in the performance of Delaware versus non-Delaware firms.

${ }^{41}$ Carhart (1997) added the momentum factor to the original three-factor model of Fama and French (1993). See these two papers for details on portfolio construction.

${ }^{42}$ The results are qualitatively similar over a three-year horizon.

${ }^{43}$ For example, if firm $A$ reincorporates from California to Delaware on August 26, then firm $A$ is a member of the non-Delaware portfolio through August 31. Firm $A$ is then reassigned to the Delaware portfolio on September 1. Gains or losses associated with reincorporation are therefore attributed to the non-Delaware portfolio. Dropping firm-month observations during the month that a firm reincorporates does not significantly affect the results.
} 
a portfolio that only buys and sells firms that existed before 1985 ("Est. before 1985"), and for a portfolio that does both ("Reincorp. exluded \& Est. before 1985"). These portfolios are designed to mitigate the selection of new or existing firms into Delaware after the shock. Most of the abnormal returns of Delaware firms can be attributed to the performance of large firms. The final two rows show that the statistical significance of these results relies on the four-factor specification, as the unconditional difference between Delaware and non-Delaware performance, while comparable in magnitude, is not statistically significant at conventional levels. However, because the statistical power of the unconditional comparison is relatively low, it is unlikely that an economically significant unconditional difference could be detected with these data.44

Figure 6 presents an historical perspective. The top panel graphs the Delaware minus non-Delaware portfolio's four-factor adjusted abnormal returns over the entire 81-year sample period (1930-2010), while the bottom panel focuses on the decade surrounding the passage of 102(b)(7). Figure 6 shows that (1) the timing of the returns aligns precisely with the years following the legal shocks and (2) this is the only period of significant positive abnormal returns in the last 60 years.

The abnormal returns are consistent with the hypothesis that the expansion of Delaware's governance network added value to Delaware firms. However, it is possible that the legal shock itself (i.e., 102(b)(7) and Moran) was responsible for the abnormal returns. Table 5 examines this alternative hypothesis by exploiting the fact that most states eventually followed Delaware's example by passing limited liability statutes and affirming the poison pill. ${ }^{45}$ The first row presents the four-factor regression for a zero-investment, value-weighted portfolio that buys firms incorporated in limited liability states and sells short all others. The second row similarly buys firms in states that have affirmed the poison pill and sells short all others. In both cases, a state exits the buy side of the portfolio the month before the legal change and enters the sell side the month after. (The month of the legal change is excluded.) The abnormal returns of both portfolios are small (2 and 7 basis points, respectively), suggesting that the legal shock itself did not cause the abnormal returns.

\footnotetext{
${ }^{44}$ The statistical power is low because the variance in equity prices is high. The standard deviation of the monthly returns for the Delaware minus non-Delaware portfolio is nearly 150 basis points. Thus, for example, the likelihood of finding a true unconditional difference of 25 basis points over a four-year period is 22 percent. In order for the statistical power to increase to 80 percent (given a 5 percent significance level), a true 25 basis point difference would have to be sustained over 23 years.

${ }^{45}$ Within 18 months, 33 other states had passed statutes similar to 102(b)(7) and 5 states had affirmed the poison pill. Most states that eventually affirmed the pill between 3.5 to 5 years after Delaware. The data on the timing of each state's affirmation of the poison pill come from table 2 of Cain, McKeon and Solomon (2017).
} 
However, the estimates are also imprecise (s.e. 19 and 23, respectively). The final row buys firms in states with both limited liability and poison pills and sells firms in states with neither limited liability nor poison pills. The abnormal return is similarly small but imprecise.

The small point estimates are consistent with the hypothesis that the abnormal returns of Delaware firms in the wake of 102(b)(7) and Moran were not driven by the change in the law itself, as similar abnormal returns did not obtain for firms in other states effecting similar changes. However, the estimates are noisy and therefore do not permit a strong inference.

\section{Robustness and Discussion}

This section gives robustness checks and an extended discussion of the results. The estimate of the network effect in incorporation decisions rests on three principal assumptions: (1) firms base incorporation decisions on Delaware's current legal quality and network size (and not on an expectation of its future legal quality or future network size), (2) Delaware legal quality is constant before and after the shock, and (3) the distributions of firms' quality and network thresholds are constant across cohorts. Stated more generally, these assumptions require that firms do not anticipate each other's decisions, and that there are no trends in law or firm type. Sections 6.1, 6.2 and 6.3 examine each of these assumptions in turn. Finally, section 6.4 considers several learning hypotheses to explain the main results.

\subsection{Rational Expectations}

This section considers how the interpretation of the results would change if firms anticipated each other's responses to the legal quality shock.46 Throughout the model, I have assumed that firms are "myopic" in that they base incorporation decisions on Delaware's current legal quality and network size. However, given that reincorporation is costly, it is plausible that firms instead base decisions on an expectation of Delaware's future legal quality and network size. Here, I consider an alternative setting in which firms base their decisions on a rational expectation of Delaware's future legal quality and network size. I will refer to this as the "rational model" and use a superscript "r.m." to denote incorporation decisions from this setting.

To gain traction on the rational model, imagine a simplified setting in which existing firms do not reincorporate. A firm's initial decision is thus once-and-for-all 47 Further suppose

\footnotetext{
${ }^{46} \mathrm{I}$ thank an anonymous referee for suggesting this line of inquiry.

${ }^{47}$ In the context of the original model, this is the case in which state dependence is "large" relative to the
} 
that the number of firms is constant over time. Since a firm survives to the next period with probability $\delta$, this means that the (normalized) size of each cohort is $1-\delta$.

A firm in the rational setting makes an incorporation decision by comparing its thresholds to an expectation of the average levels of legal quality and network size over the firm's (expected) lifecycle. Thus, a firm's initial decision is the same as in the original model (equation 3), except current levels of legal quality and network size are replaced with average expected levels of legal quality and network size. Letting $m_{t}(\cdot)$ denote such an expectation formed at time $t$, a firm's initial decision is

$$
X_{i j t=j}^{\mathrm{r} . \mathrm{m} .}=I\left(m_{t}(Q)>q_{i t}\right) \times I\left(m_{t}\left(\bar{X}^{\mathrm{r} . \mathrm{m} \cdot}\right)>n_{i}\right) .
$$

Average expected legal quality as of time $t$ is a weighted average of expected legal quality over all future periods, where each period's weight is proportional to the probability that a time- $t$ firm survives to that period. Formally,

$$
m_{t}(Q)=\sum_{s=t}^{\infty} E_{t}\left(Q_{s}\right) w_{s}
$$

where $w_{s}=\delta^{s-t}(1-\delta)$ and $E_{t}(\cdot)$ denotes an expectation formed at time $t 48$ This is straightforward to compute because, by assumption 1, legal quality changes only once and unexpectedly. Expected quality in any future period is therefore always equal to current quality, and average expected quality over a firm's lifecycle is

$$
m_{t}(Q)=Q_{t}= \begin{cases}Q_{0} & \text { if } t<1 \\ Q_{0}+\Delta Q & \text { if } t \geq 1\end{cases}
$$

A firm's average expected network size is similarly defined as

$$
m_{t}\left(\bar{X}^{\text {r.m. }}\right)=\sum_{s=t}^{\infty} E_{t}\left(\bar{X}_{s}^{\text {r.m. }}\right) w_{s},
$$

and Delaware's share of new firms is therefore

$$
\bar{X}_{\cdot t t}^{\mathrm{r} . \mathrm{m} .}=F\left(Q_{t}\right) G\left(m_{t}\left(\bar{X}^{\mathrm{r} \cdot \mathrm{m} .}\right)\right)
$$

legal shock and existing firms do not experience random shocks (i.e., $b_{q}$ and $b_{n}$ sufficiently large and $r=0$ ). ${ }^{48}$ Note that $w_{s}$ is proportional to $\delta^{s-t}$ (the probability of surviving to period $s$ ) and $\sum_{s=t}^{\infty} w_{s}=1$. 
It is straightforward to show that, in this setting, the quality effect estimator (from section 3.1) is an upper bound on the true quality effect, while the network effect estimator (from section 3.2 is a lower bound on the true network effect. That is,

$$
\sigma \leq \frac{\Delta \bar{X}_{\cdot 11}^{\mathrm{r} \cdot \mathrm{m}}}{\bar{X}_{.00}^{\mathrm{r} . \mathrm{m} \cdot}}
$$

and

$$
\gamma \geq \frac{\bar{X}^{* \mathrm{r} . \mathrm{m} .}-\bar{X}_{\cdot 11}^{\mathrm{r} . \mathrm{m} .}}{\bar{X}_{\cdot 11}^{\mathrm{rm} .}}
$$

The proof is given in appendix section A.4. Intuitively, the legal quality estimator uses the first post-shock cohort to measure the immediate change in Delaware's share of new firms. However, the first post-shock cohort responds not only to the increase in Delaware's legal quality but also to the (expected) increase in its future network size. Delaware's share of the first post-shock cohort is therefore greater than what the quality effect alone would have

induced. Similarly, the network effect estimator uses firms from the second post-shock cohort and onwards to measure subsequent changes in Delaware's share of new firms. This estimator is a lower bound because it excludes the part of the increase in Delaware's share of the first post-shock cohort that was due to the expected increase in network size. Note that this logic does not depend on the accuracy of firms' predictions, the ability of firms to reincorporate, or the total number of firms; the validity of the bounds depends only on firms' beliefs that a positive quality shock will (weakly) increase Delaware's network size. The bounds are thus valid even if firms systematically underestimate Delaware's future network size.

However, because the distributions of legal quality and network thresholds are unknown, it is not possible to use the data to determine whether post-shock firms anticipated the growth in Delaware's network. Future studies could investigate this by beginning with a perhaps more basic question, namely, whether corporate decision-makers form rational expectations over future governance trends. To answer this question, one could survey directors or corporate attorneys over their beliefs regarding Delaware's future network size (or any other governance trend) and then compare these predictions to their realized values.

\subsection{Trends in Legal Quality}

Delaware corporate law changes frequently. These changes are often later adopted by other states and the Model Act (Romano, 1985). This presents a challenge because the method of measuring the magnitude of network effects relies on estimates of pre- and post- 
shock steady states. Estimating these steady states in turn requires a long time horizon during which the legal landscape is relatively constant. For this reason, significant changes in Delaware (and non-Delaware) law before and after 1985/1986 could bias the estimates in unknown directions.

Importantly, however, the method employed in this paper does not require that the actual content of Delaware law remain constant over the entire estimation window. Instead, it only requires that other shocks have little or no net impact on average incorporation decisions. Figure 1 (also discussed above) offers suggestive evidence that this is the case, specifically, that the net effect of unobserved legal shocks in any given pre- or post-shock year is small. Figure 1 graphs the annual rate at which non-Delaware firms reincorporate to Delaware. Over the 30-year window surrounding the passage of 102(b)(7) (1972-2002), the rate is relatively constant. The sole exception is the five-fold spike during the two years following Moran and 102(b)(7). Thus, even if the content of the law changed significantly throughout this period, the magnitude of the net effect of these changes, as reflected by reincorporation rates, is relatively small.

\subsection{Trends in Firm Type}

I next consider the possibility that the composition of firm types was not stable throughout the estimation window. The steady state assumption yields a simple and strong prediction for the pre-shock period: If both law and firm type distributions are constant, then new firm shares are also constant 49 Figure 7 graphs new firm shares over time (as in figure 2), and includes the 95 percent confidence interval computed separately for each year. For reference, the horizontal line at 0.29 marks the estimate of the pre-shock steady-state from table 2. I cannot reject the joint hypothesis that the 5 (or fewer) years preceding the shock are all equal to 0.29 ( $p$-value of 0.6 for the 5-year joint hypothesis), but I can reject the joint hypothesis that the 6 (or more) years preceding the shock are all equal to 0.29. Similarly, there is a very small but statistically significant downward trend in new firm shares over both the 10- and 20-year period leading up to the shock. The coefficients are approximately $1 / 4$ th and $1 / 5$ th of a percentage point per year, respectively. ${ }^{50}$ Finally, there is no significant trend over the 56-year pre-shock period.

\footnotetext{
${ }^{49}$ In fact, the prediction is even more general. Not only should the Delaware share of new firms be constant over time, but so should the Delaware share of 1-year old firms, 2-year old firms, and so on. To use the notation of the model, $\bar{X}_{j t}=\bar{X}_{j+s, t+s}, \forall s, \forall t \leq 0$.

${ }^{50}$ These trends were estimated by regressing an indicator for incorporating in Delaware on year, using the relevant sample period.
} 
The variance in new firm shares is more than what would randomly obtain were the law and firm type distributions actually fixed; however, I conclude that the net bias on the estimates is relatively small. There are several reasons. First, the magnitude of this variance is small relative to the legal shock I study. Moreover, the effect of this variance on the Delaware share of all firms (the relevant statistic through which network effects operate) is even smaller; on average, new firms account for only 5 percent of that statistic in any given year. Relatedly, the slight, pre-shock downward trend suggests that firms' thresholds may be exogenously increasing over time. To the extent that this trend persisted in postshock periods, this would downwardly-bias the total effect of the shock. Again, however, the magnitude of this trend is not practically significant.

Even if there were no pre-shock trends, it is possible that 102(b)(7) and Moran caused post-shock trends through the selection of private firms into public markets. For example, it may have caused non-Delaware firms to delay or forgo their initial public offering, thereby increasing Delaware's post-shock share of new firms. However, to the extent this selection is constant, its effect would be reflected immediately. Thus, a constant selection effect would change the interpretation of the quality effect but not bias estimates of the contribution of network effects. Further, such a selection effect may be unlikely given the relatively low barriers to reincorporation for private firms, as reflected by the frequency with which firms reincorporate immediately before going public.

A related issue to trends in firm type is trends in firm-specific shocks (the parameter $r$ in the model). Figure 1 gives suggestive evidence that $r$ may not be constant over the very long run. The model predicts that the reincorporation rate is constant in pre-shock periods, spikes in immediate post-shock periods, and then (eventually) achieves a new steady-state level that is strictly greater than the pre-shock level (see appendix section A.3). Figure 1 shows that this was the case over the 30-year period surrounding 102(b)(7). However, starting in the 2000s, the reincorporation rate declined and eventually dipped below preshock levels. Yet, over the same period, the Delaware share of new firms was increasing. In the context of the model, this can be explained by a downward trend in the likelihood of a firm-specific shock. If this trend actually began near the time of shock, then estimates of state dependence would be biased upward. Alternatively, it could be that $r$ varies with non-Delaware firms' thresholds (specifically, that it is negatively correlated with $q$ or $n$ ). Even so, given the magnitude and timing of this decline, I conclude that potential trends in firm-specific shocks are not practically significant. 


\subsection{Learning}

It is plausible that firms did not immediately understand how 102(b)(7) and Moran affected the intrinsic quality of Delaware law, and that firms learned the true effect over time. This would seem justified by the data for two reasons: (1) most of the effect of the legal shock on incorporation decisions manifested over time and (2) Delaware firms earned abnormal returns in post-shock years, which suggests investors did not price the true (total) effect. Thus, if the effect of the legal change on incorporation decisions and firm value were unknown to investors as of the time of the shock, it stands to reason that its effect on legal quality could have also been uncertain to managers.

Whether this challenges the interpretation of the results depends on the particular type of learning mechanism at work. To see this, suppose firms form beliefs over the effect of the legal shock, but there is some uncertainty or error. Next consider a partition of learning mechanisms into two types. In the first type, firms use changes in other firms' behavior to refine their belief. In the second type, firms do not use changes in other firms' behavior to refine their belief. By construction, the first type is a network effect because a firm's belief (and therefore decision) is directly affected by other firms' decisions. The canonical herding hypothesis would belong to this category. The presence of this first type of mechanism is therefore consistent with this paper's claim that firms are strongly influenced by each other's decisions.

The second type of mechanism could challenge the interpretation. Yet there are still some conditions under which it would not. For example, if firms' estimates of the effect of the shock on legal quality were increasing over time because actual legal quality increased as a consequence of a larger network, then this, too, would be a network effect. Specifically, this would be a positive consumption externality. If, however, firms' estimates were increasing over time because firms had previously underestimated the true immediate effect of the shock on legal quality, then this would not be a network effect. This would be a bias correction over time. Thus, if firms systematically underestimated the joint value of 102(b)(7) and Moran, and further if this bias were later corrected, then this paper's estimates would overstate the magnitude of the network effect. One interpretation of the abnormal returns from section 5.3 is that investors did this for 3 to 4 years. Even still, the abnormal returns dissipate by the fifth year, at which point about half of the long-run gains in new firm shares had obtained. Thus, even a conservative estimate would still allocate approximately half of the gains in Delaware's share to network effects. Moreover, it seems a priori improbable that managers' bias would persist over a decade or more. The enactment of 102(b)(7) in particular was a 
highly-publicized event that significantly affected mangers' personal wealth. Managers would therefore be motivated to produce an accurate estimate of the effect of 102(b)(7) on the value of incorporating in Delaware (if not to the firm, then at least to themselves). Indeed, the market for directors and officers insurance implicitly provides one such estimate.

A final possibility is that the true value of $102(\mathrm{~b})(7)$ or the poison pill is increasing over time. For example, it could be that the opportunity cost or likelihood of litigation increased over time. However, this is not a learning hypothesis, but instead a post-shock trend in the law. As noted above, if this trend were significant, we would expect it to lead to increasing reincorporation rates. I instead find that reincorporation rates are constant and eventually declining over the post-shock period. This hypothesis is also refuted by the fact that most states followed Delaware's legal changes within 5 years. Firms located in such states would therefore not have to incorporate in Delaware to obtain the benefits of the legal change itself.

\section{Conclusion}

I found strong evidence of network effects in corporate governance decisions. The fraction of U.S. public companies incorporating in Delaware, roughly constant for half a century, more than doubled after Delaware simultaneously affirmed the poison pill and extended limited liability to directors. I attributed more than half of this change to a cascading effect in which governance decisions of existing firms successively influence future cohorts. I conclude that firms strongly influence each other's corporate governance decisions.

\section{Appendix A Derivations}

\section{A.1 Legal Quality Effect, $\sigma$}

$$
\begin{aligned}
\sigma\left(Q_{0}, Q_{0}+\Delta Q\right) & =\frac{F\left(Q_{0}+\Delta Q\right)-F\left(Q_{0}\right)}{F\left(Q_{0}\right)} \\
& =\frac{F\left(Q_{0}+\Delta Q\right) G\left(\bar{X}_{0}\right)-F\left(Q_{0}\right) G\left(\bar{X}_{-1}\right)}{F\left(Q_{0}\right) G\left(\bar{X}_{-1}\right)} \\
& =\frac{\Delta \bar{X}_{.11}}{\bar{X}_{.00}}
\end{aligned}
$$


The second equality holds because the system is in steady state at time $t=0$ (by assumption 1 and so $\bar{X}_{-1}=\bar{X}_{0}$. The final equality follows from equation 3 .

\section{A.2 Network Effect, $\widetilde{\gamma}$}

$$
\begin{aligned}
\widetilde{\gamma}\left(\bar{X}_{t-1}, \bar{X}_{t}\right) & =\frac{G\left(\bar{X}_{t}\right)-G\left(\bar{X}_{t-1}\right)}{G\left(\bar{X}_{t-1}\right)} \\
& =\frac{F\left(Q_{t+1}\right) G\left(\bar{X}_{t}\right)-F\left(Q_{t}\right) G\left(\bar{X}_{t-1}\right)}{F\left(Q_{t}\right) G\left(\bar{X}_{t-1}\right)} \\
& =\frac{F\left(Q_{t}\right) G\left(\bar{X}_{t}\right)-F\left(Q_{t}\right) G\left(\bar{X}_{t-1}\right)}{F\left(Q_{t}\right) G\left(\bar{X}_{t-1}\right)} \\
& =\frac{\Delta \bar{X}_{\cdot t^{+} t^{+}}}{\bar{X}_{t t}}
\end{aligned}
$$

The third equality holds by assumption 1 because $t>1$.

\section{A.3 State Dependence of Non-Delaware Firms' Quality Threshold, $\beta$}

Let $p_{t}$ denote the time- $t$ reincorporation rate for non-Delaware firms, that is, the probability that a firm is incorporated in Delaware at time $t$ conditional on it being incorporated in non-Delaware at time $t-1$ :

$$
\begin{aligned}
p_{t}= & \operatorname{Pr}\left(X_{i j t}=1 \mid X_{i j t^{-}}=0\right) \\
= & \operatorname{Pr}\left(\omega_{i t}=S\right) \times \operatorname{Pr}\left(X_{i j t}=1 \mid X_{i j t^{-}}=0, \omega_{i t}=S\right)+ \\
& \operatorname{Pr}\left(\omega_{i t} \neq S\right) \times \operatorname{Pr}\left(X_{i j t}=1 \mid X_{i j t^{-}}=0, \omega_{i t} \neq S\right) .
\end{aligned}
$$

The second expression decomposes the non-Delaware reincorporation rate into two components: (1) a baseline rate induced by idiosyncratic shocks that persists in steady state and (2) an additional component induced by changes in legal quality or average firm behavior. The second term is positive only if these changes are positive $\left(\Delta Q_{t}>0\right.$ or $\left.\Delta \bar{X}_{t-1}>0\right)$. 
In pre-shock periods $(t \leq 0)$, the transition probability is in steady state. In particular,

$$
\begin{aligned}
p_{t \leq 0} & =r F\left(Q_{t}\right) G\left(\bar{X}_{t^{-}}\right) \\
& =r \bar{X}_{t t} \\
& =r \bar{X}_{t}
\end{aligned}
$$

and so $r$ is identified in the pre-shock period.

In the period immediately following the shock, both components of the transition probability increase:

$$
\begin{aligned}
p_{1}=r \times \underbrace{F\left(Q_{0}+\Delta Q\right) G\left(\bar{X}_{0}\right)}_{\begin{array}{c}
\text { new baseline rate induced by } \\
\text { random firm-specific shocks } \\
=\bar{X} \cdot 11
\end{array}}+ \\
(1-r) \times \underbrace{\frac{F\left(Q_{0}+\Delta Q-\widetilde{b}_{q}^{0}\right) G\left(\bar{X}_{0}\right)-F\left(Q_{0}\right) G\left(\bar{X}_{-1}\right)}{1-F\left(Q_{0}\right) G\left(\bar{X}_{-1}\right)}}_{\text {increase to baseline induced by } \Delta Q},
\end{aligned}
$$

which implies

$$
\begin{aligned}
F\left(Q_{0}+\Delta Q-\widetilde{b}_{q}^{0}\right) G\left(\bar{X}_{0}\right)-F\left(Q_{0}\right) G\left(\bar{X}_{-1}\right) & =\frac{\left(p_{1}-r \bar{X}_{\cdot 11}\right)\left(1-\bar{X}_{.00}\right)}{1-r} \\
& =p_{1}\left(1-\bar{X}_{\cdot 00}\right)-\frac{r\left(1-\bar{X}_{.00}\right)\left(\bar{X}_{\cdot 11}-p_{1}\right)}{1-r}
\end{aligned}
$$

Thus, we have

$$
\begin{aligned}
\beta\left(Q_{0}, Q_{0}+\Delta Q\right) & =\frac{\left(F\left(Q_{0}+\Delta Q\right)-F\left(Q_{0}+\Delta Q-\widetilde{b}_{q}^{0}\right)\right) / F\left(Q_{0}\right)}{\sigma\left(Q_{0}, Q_{0}+\Delta Q\right)} \\
& =1-\frac{F\left(Q_{0}+\Delta Q-\widetilde{b}_{q}^{0}\right)-F\left(Q_{0}\right)}{F\left(Q_{0}+\Delta Q\right)-F\left(Q_{0}\right)} \\
& =1-\frac{F\left(Q_{0}+\Delta Q-\widetilde{b}_{q}^{0}\right) G\left(\bar{X}_{0}\right)-F\left(Q_{0}\right) G\left(\bar{X}_{-1}\right)}{F\left(Q_{0}+\Delta Q\right) G\left(\bar{X}_{0}\right)-F\left(Q_{0}\right) G\left(\bar{X}_{-1}\right)} \\
& =1-\left(\frac{p_{1}\left(1-\bar{X}_{\cdot 00}\right)}{\Delta \bar{X}_{\cdot 11}}-\frac{r\left(1-\bar{X}_{.00}\right)\left(\bar{X}_{\cdot 11}-p_{1}\right)}{(1-r) \Delta \bar{X}_{\cdot 11}}\right) \\
& =\frac{\Delta \bar{X}_{\cdot 11}-p_{1}\left(1-\bar{X}_{.00}\right)}{\Delta \bar{X}_{\cdot 11}}+\xi
\end{aligned}
$$


where

$$
\xi=\frac{r}{1-r} \times \frac{1-\bar{X}_{\cdot 00}}{\Delta \bar{X}_{\cdot 11}} \times\left(\bar{X}_{\cdot 11}-p_{1}\right) .
$$

To get from the second to third equality of equation 34. I multiply the second term by $G\left(\bar{X}_{0}\right) / G\left(\bar{X}_{0}\right)$ and replace some $G\left(\bar{X}_{0}\right)$ terms with $G\left(\bar{X}_{-1}\right)$. This replacement is valid because we begin in steady state (assumption 1 ) and so $\bar{X}_{0}=\bar{X}_{-1}$. Note $\xi>0$ if and only if $r>0$ and $\bar{X}_{0}<1$.

\section{A.4 Estimating Quality and Network Effects in the Rational Set- ting}

If $m_{1} \geq m_{0}$, then the quality effect estimator from section 3.1 is an upper bound of the true quality effect because

$$
\begin{aligned}
\sigma\left(Q_{0}, Q_{0}+\Delta Q\right) & =\frac{F\left(Q_{0}+\Delta Q\right)-F\left(Q_{0}\right)}{F\left(Q_{0}\right)} \\
& =\frac{F\left(Q_{0}+\Delta Q\right) G\left(m_{0}\right)-F\left(Q_{0}\right) G\left(m_{0}\right)}{F\left(Q_{0}\right) G\left(m_{0}\right)} \\
& \leq \frac{F\left(Q_{0}+\Delta Q\right) G\left(m_{1}\right)-F\left(Q_{0}\right) G\left(m_{0}\right)}{F\left(Q_{0}\right) G\left(m_{0}\right)} \\
& =\frac{\Delta \bar{X}_{.11}^{\text {r.m. }}}{\bar{X}_{\cdot 00}^{\text {r.m. }}} .
\end{aligned}
$$

$m_{1} \geq m_{0}$ implies that an unexpected positive quality shock induces firms to revise expectations of Delaware's network size (weakly) upwards. (Note that this does not require firms to correctly estimate quality and network effects; it only requires that they expect the total effect will be positive.) If expectations are rational (and therefore do not systematically deviate from realized values), then $m_{1} \geq m_{0}$ is empirically validated because Delaware's actual post-shock network size is significantly greater than its pre-shock network size (figure 2).

Similarly, if $m_{1} \geq \bar{X}_{1}$, then the network effect estimator from section 3.2 is a lower bound 
on the true network effect because

$$
\begin{aligned}
\gamma & =\left(\prod_{t=1}^{\infty} 1+\widetilde{\gamma}\left(\bar{X}_{t-1}, \bar{X}_{t}\right)\right)-1 \\
& =\frac{F\left(Q_{1}\right) G\left(\bar{X}^{* \mathrm{r} . \mathrm{m} .}\right)}{F\left(Q_{1}\right) G\left(\bar{X}_{1}\right)}-1 \\
& \geq \frac{F\left(Q_{1}\right) G\left(\bar{X}^{* \text { r.m. }}\right)}{F\left(Q_{1}\right) G\left(m_{1}\right)}-1 \\
& =\frac{\bar{X}^{\text {*r.m. }}-\bar{X}_{\cdot 11}^{\text {r.m. }}}{\bar{X}_{\cdot 11}^{\text {r.m. }}} .
\end{aligned}
$$

$m_{1} \geq \bar{X}_{1}$ implies that the first post-shock cohort expects that Delaware's post-shock network size will continue to (weakly) increase after the first post-shock year. If expectations are rational, then $m_{1} \geq \bar{X}_{1}$ is also empirically validated because Delaware's actual post-shock network size is strictly increasing throughout post-shock years (figure 2). Note that the second equality (line 37 requires that $\lim _{t \rightarrow \infty} \bar{X}_{t}^{\text {r.m. }}$ exists (i.e., that Delaware's post-shock network size is in fact converging to some steady state) and that $G(\cdot)$ is continuous at that new steady state; otherwise, the cumulative network effect, $\gamma$, is not defined.

\section{References}

Arsht, S Samuel and Walter K Stapleton, "Delaware's New General Corporation Law: Substantive Changes," The Business Lawyer, 1967, pp. 75-93.

Banerjee, Abhijit V, "A Simple Model of Herd Behavior," The Quarterly Journal of Economics, 1992, 107 (3), 797-817.

Bar-Gill, Oren, Michal Barzuza, and Lucian Bebchuk, "The Market for Corporate Law," Journal of Institutional and Theoretical Economics, 2006, 162 (1), 134-160.

Bebchuk, Lucian, Alma Cohen, and Allen Ferrell, "Does the Evidence Favor State Competition in Corporate Law?," California Law Review, 2002, pp. 1775-1821.

Bebchuk, Lucian Arye, "Federalism and the Corporation: The Desirable Limits on State Competition in Corporate Law," Harvard Law Review, 1992, 5 (7), 1435-1510.

_ and Alma Cohen, "Firms' Decisions Where to Incorporate," Journal of Law and Economics, 2003, $46(2), 383-425$. 
- and Assaf Hamdani, "Vigorous Race or Leisurely Walk: Reconsidering the Competition over Corporate Charters," Yale Law Journal, 2002, 112 (3), 553-615.

- and Mark J Roe, "A Theory of Path Dependence in Corporate Ownership and Governance," Stanford Law Review, 1999, pp. 127-170.

Becht, Marco, Patrick Bolton, and Ailsa Röell, "Corporate Law and Governance," in A. Mitchell Polinsky and Steven Shavell, eds., Handbook of Law and Economics, Vol. 2, Elsevier, October 2007, chapter 12, pp. 829-943.

Bhagat, Sanjai and Roberta Romano, "Event Studies and the Law: Part II: Empirical Studies of Corporate Law," American Law and Economics Review, 2002, 4 (2), 380-423.

Bikhchandani, Sushil, David Hirshleifer, and Ivo Welch, "A Theory of Fads, Fashion, Custom, and Cultural Change as Informational Cascades," Journal of political Economy, 1992, 100 (5), 992-1026.

Bizjak, John M, Michael L Lemmon, and Lalitha Naveen, "Does the Use of Peer Groups Contribute to Higher Pay and Less Efficient Compensation?," Journal of Financial Economics, 2008, 90 (2), 152-168.

Bizjak, John, Michael Lemmon, and Thanh Nguyen, "Are All CEOs Above Average? An Empirical Analysis of Compensation Peer Groups and Pay Design," Journal of Financial Economics, 2011, 100 (3), 538-555.

Black, Bernard, Brian Cheffins, and Michael Klausner, "Outside Director Liability," Stanford Law Review, 2005, 58, 1055.

Bramoullé, Yann, Habiba Djebbari, and Bernard Fortin, "Identification of Peer Effects Through Social Networks," Journal of Econometrics, 2009, 150 (1), 41-55.

Bratton, William W and Joseph A McCahery, "The Equilibrium Content of Corporate Federalism," Wake Forest Law Review, 2006, 41, 619.

Brock, William A and Steven N Durlauf, "Discrete Choice with Social Interactions," The Review of Economic Studies, 2001, 68 (2), 235-260.

Broughman, Brian, Jesse M Fried, and Darian Ibrahim, "Delaware Law as Lingua Franca: Theory and Evidence," Journal of Law and Economics, 2014, 57 (4), 865-895. 
Cain, Matthew D, Stephen B McKeon, and Steven Davidoff Solomon, "Do Takeover Laws Matter? Evidence from Five Decades of Hostile Takeovers," Journal of Financial Economics, 2017, 124 (3), 464-485.

Carhart, Mark M, "On Persistence in Mutual Fund Performance," Journal of Finance, 1997, 52 (1), 57-82.

Cary, William L, "Federalism and Corporate Law: Reflections upon Delaware," Yale Law Journal, 1974, 83 (4), 663-705.

Catan, Emiliano $M$ and Marcel Kahan, "The Law and Finance of Antitakeover Statutes," Stanford Law Review, 2016, 68, 629.

Coffee, John C, "Future as History: The Prospects for Global Convergence in Corporate Governance and Its Implications," Northwestern University Law Review, 1998, 93, 641708.

Corroon, Richard F, "The Proposed New Delaware Corporation Statute," Journal of Legal Education, 1967, 20, 522 .

Cremers, Martijn and Allen Ferrell, "Thirty Years of Shareholder Rights and Firm Value," Journal of Finance, 2014, 69 (3), 1167-1196.

Daines, Robert, "Does Delaware Law Improve Firm Value?," Journal of Financial Economics, 2001, 62 (3), 525-558.

_ , "The Incorporation Choices of IPO Firms," New York University Law Review, 2002, 77, 1559-1611.

Dammann, Jens and Matthias Schündeln, "The Incorporation Choices of Privately Held Corporations," Journal of Law, Economics, \& Organization, 2009, 27 (1), 79-112.

Dykstra, Daniel J, "The Revival of the Derivative Suit," University of Pennsylvania Law Review, 1967, 116 (1), 74-101.

Easterbrook, Frank H and Daniel R Fischel, The Economic Structure of Corporate Law, Harvard University Press, 1996.

Eldar, Ofer and Lorenzo Magnolfi, "Regulatory Competition and the Market for Corporate Law," Manuscript, 2017. 
Fama, Eugene F and Kenneth R French, "Common Risk Factors in the Returns on Stocks and Bonds," Journal of Financial Economics, 1993, 33 (1), 3-56.

Fisch, Jill E, "The Peculiar Role of the Delaware Courts in the Competition for Corporate Charters," University of Cincinnati Law Review, 1999, 68, 1061-1100.

Fischel, Daniel R, "The Business Judgment Rule and the Trans Union Case," The Business Lawyer, 1985, pp. 1437-1455.

Gaviria, Alejandro and Steven Raphael, "School-Based Peer Effects and Juvenile Behavior," Review of Economics and Statistics, 2001, 83 (2), 257-268.

Gilson, Ronald J, "Globalizing Corporate Governance: Convergence of Form or Function," The American Journal of Comparative Law, 2001, 49 (2), 329-358.

Gompers, Paul, Joy Ishii, and Andrew Metrick, "Corporate Governance and Equity Prices," Quarterly Journal of Economics, 2003, 118 (1), 107-156.

Graham, Bryan S, "Identifying Social Interactions Through Conditional Variance Restrictions," Econometrica, 2008, 76 (3), 643-660.

Grinblatt, Mark, Sheridan Titman, and Russ Wermers, "Momentum Investment Strategies, Portfolio Performance, and Herding: A Study of Mutual Fund Behavior," American Economic Review, 1995, pp. 1088-1105.

Hadfield, Gillian and Eric Talley, "On Public Versus Private Provision of Corporate Law," Journal of Law, Economics, and Organization, 2006, 22 (2), 414-441.

Hansmann, Henry and Reinier Kraakman, "The End of History for Corporate Law," Georgetown Law Journal, 2001, 89, 439-468.

Heckman, James J, "Heterogeneity and State Dependence," in "Studies in Labor Markets," University of Chicago Press, 1981, pp. 91-140.

Heron, Randall A and Wilbur G Lewellen, "An Empirical Analysis of the Reincorporation Decision," Journal of Financial and Quantitative Analysis, 1998, 33 (4), 549-568.

Holmström, Bengt and Steven N Kaplan, "Corporate Governance and Merger Activity in the United States: Making Sense of the 1980s and 1990s," Journal of Economic Perspectives, 2001, 15 (2), 121-144. 
Kahan, Marcel and Ehud Kamar, "The Myth of State Competition in Corporate Law," Stanford Law Review, 2002, pp. 679-749.

_ and Michael Klausner, "Standardization and Innovation in Corporate Contracting (or "The Economics of Boilerplate")," Virginia Law Review, 1997, pp. 713-770.

Kamar, Ehud, "A Regulatory Competition Theory of Indeterminacy in Corporate Law," Columbia Law Review, 1998, pp. 1908-1959.

Katz, Michael L and Carl Shapiro, "Technology Adoption in the Presence of Network Externalities," Journal of Political Economy, 1986, 94 (4), 822-841.

Klausner, Michael, "Corporations, Corporate law, and Networks of Contracts," Virginia Law Review, 1995, 81, 757-882.

Manski, Charles F, "Identification of Endogenous Social Effects: The Reflection Problem," The Review of Economic Studies, 1993, 60 (3), 531-542.

Netter, Jeffry and Annette Poulsen, "State Corporation Laws and Shareholders: The Recent Experience," Financial Management, 1989, pp. 29-40.

Nofsinger, John R and Richard W Sias, "Herding and Feedback Trading by Institutional and Individual Investors," Journal of Finance, 1999, 54 (6), 2263-2295.

Romano, Roberta, "Law as a Product: Some Pieces of the Incorporation Puzzle," Journal of Law, Economics, and Organization, 1985, 1, 225.

_, The Genius of American Corporate Law, AEI press, 1993.

_, "The States as a Laboratory: Legal Innovation and State Competition for Corporate Charters," Yale Journal on Regulation, 2006, 23, 209.

- and Sarath Sanga, "The Private Ordering Solution to Multiforum Shareholder Litigation," Journal of Empirical Legal Studies, 2017, 14 (1), 31-78.

Sacerdote, Bruce, "Peer Effects with Random Assignment: Results for Dartmouth Roommates," Quarterly Journal of Economics, 2001, 116 (2), 681-704.

Sanga, Sarath, "Choice of Law: An Empirical Analysis," Journal of Empirical Legal Studies, December 2014, 11, 894-928. 
Spamann, Holger, "Monetary Liability for Breach of the Duty of Care?," Journal of Legal Analysis, 2016, 8 (2), 337-373.

Subramanian, Guhan, "The Influence of Antitakeover Statutes on Incorporation Choice: Evidence on the "Race" Debate and Antitakeover Overreaching," University of Pennsylvania Law Review, 2002, 150 (6), 1795-1873.

_, "The Disappearing Delaware Effect," Journal of Law, Economics, and Organization, 2004, 20 (1), 32-59.

Talley, Eric L, "Corporate Inversions and the Unbundling of Regulatory Competition," Virginia Law Review, 2015, 101, 1649-1751.

Winter, Ralph K, "State Law, Shareholder Protection, and the Theory of the Corporation," The Journal of Legal Studies, 1977, 6 (2), 251-292.

Zwiebel, Jeffrey, "Corporate Conservatism and Relative Compensation," Journal of Political Economy, 1995, pp. 1-25. 


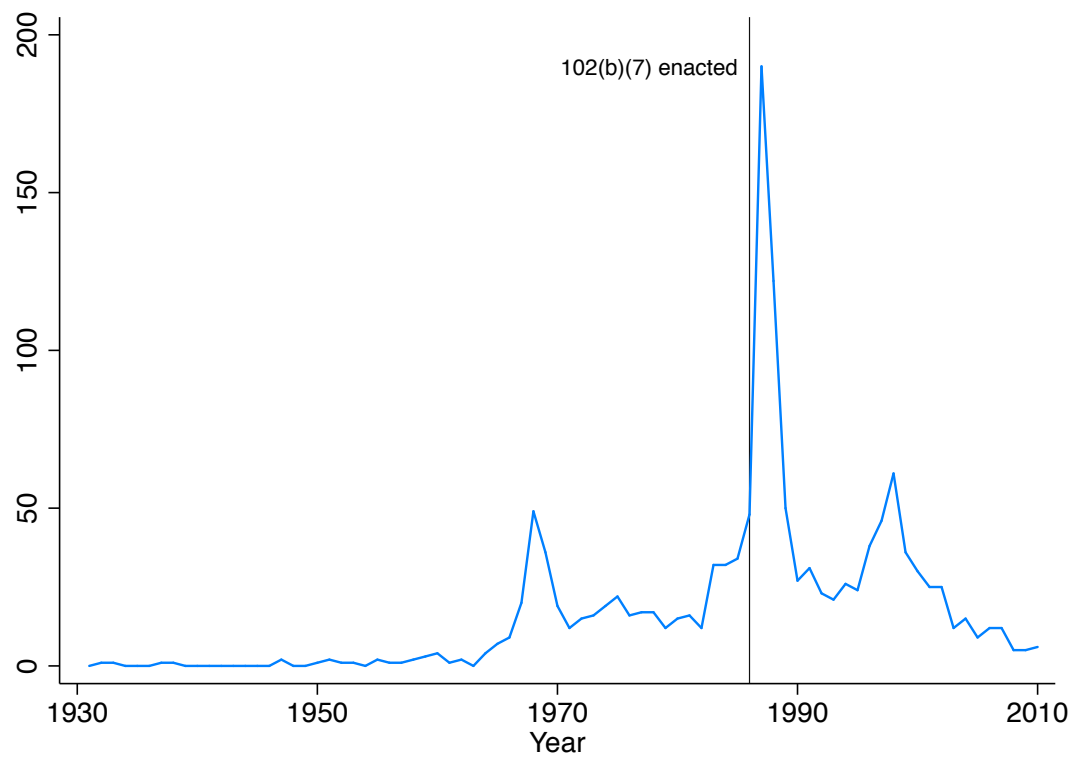

(a) Number

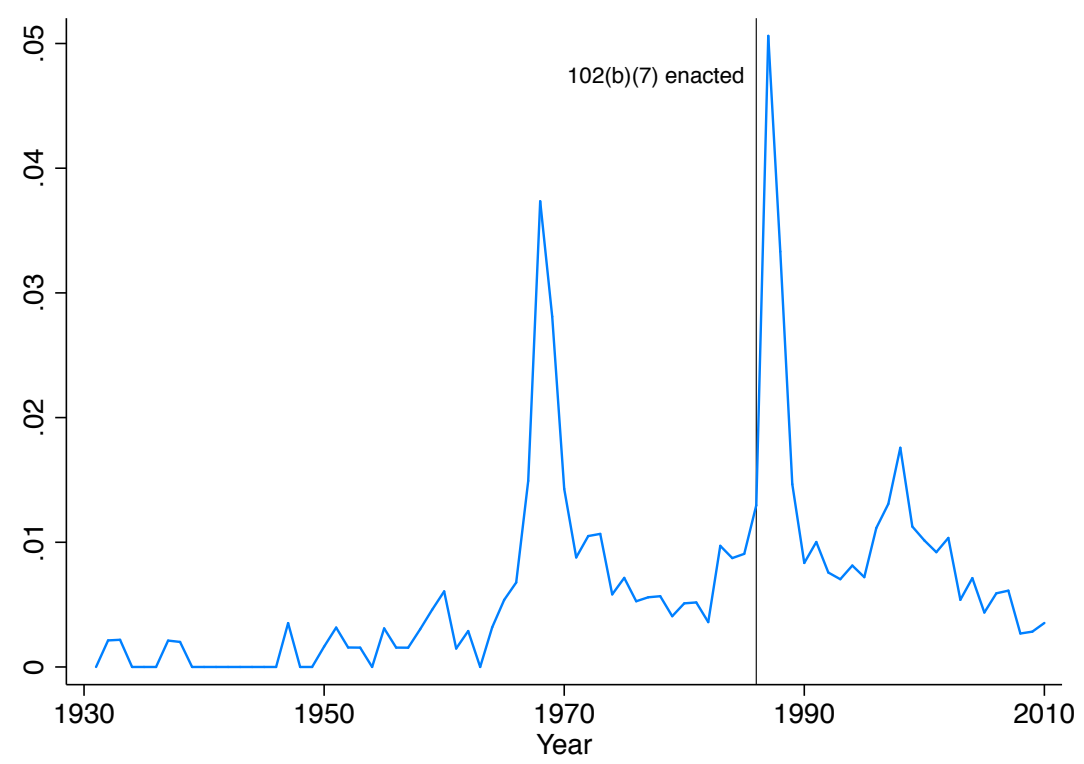

(b) Rate

Figure 1: Reincorporations to Delaware

Number and rate of non-Delaware public corporations reincorporating to Delaware. The sample is all U.S.domiciled public corporations listed on NYSE, AMEX, or NASDAQ. The identity of these companies comes from the securities price data published by CRSP, which was expanded in 1963 to include AMEX and again in 1973 to include NASDAQ. 


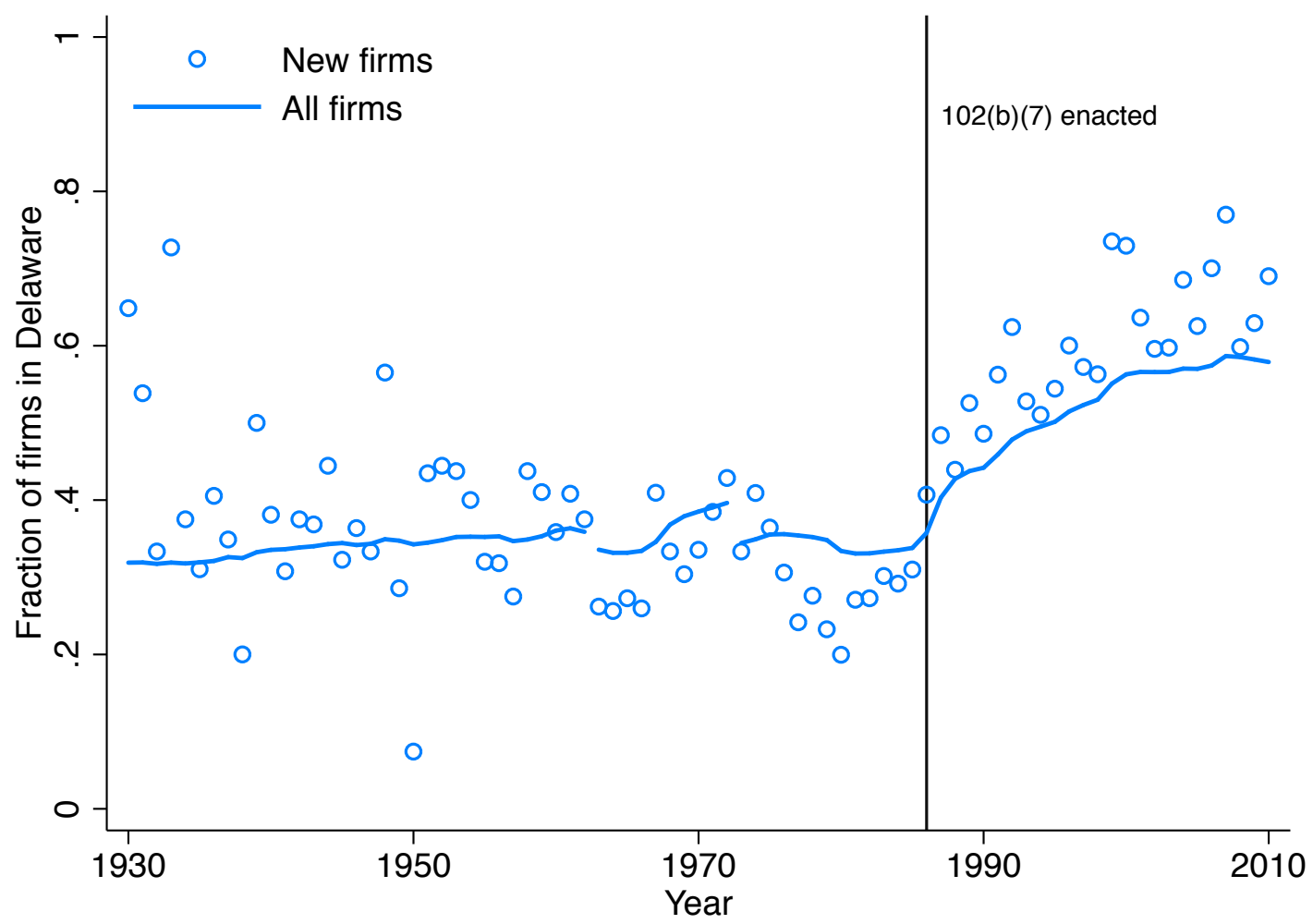

Figure 2: Delaware share of new and existing corporations, 1930-2010

The sample is all U.S.-domiciled public corporations listed on NYSE, AMEX, or NASDAQ. The identity of these companies comes from the securities price data published by CRSP, which was expanded in 1963 to include AMEX and again in 1973 to include NASDAQ. These two expansions are reflected on the graph by discontinuities in existing firm shares in 1963 and 1973. A firm is defined as "new" during the calendar year of its initial public offering. The vertical line at 1986 indicates the year the Delaware legislature passed section 102(b)(7), which enables corporations ex ante to waive monetary liability for directors who breach the duty of care. The post-shock response corresponds to the simulation given in figure $4 \mathrm{~b}$, suggesting that incorporation decisions are state-dependent, depend on legal quality, and exhibit network effects. Tables 2 and 3 present estimates of these three effects. 


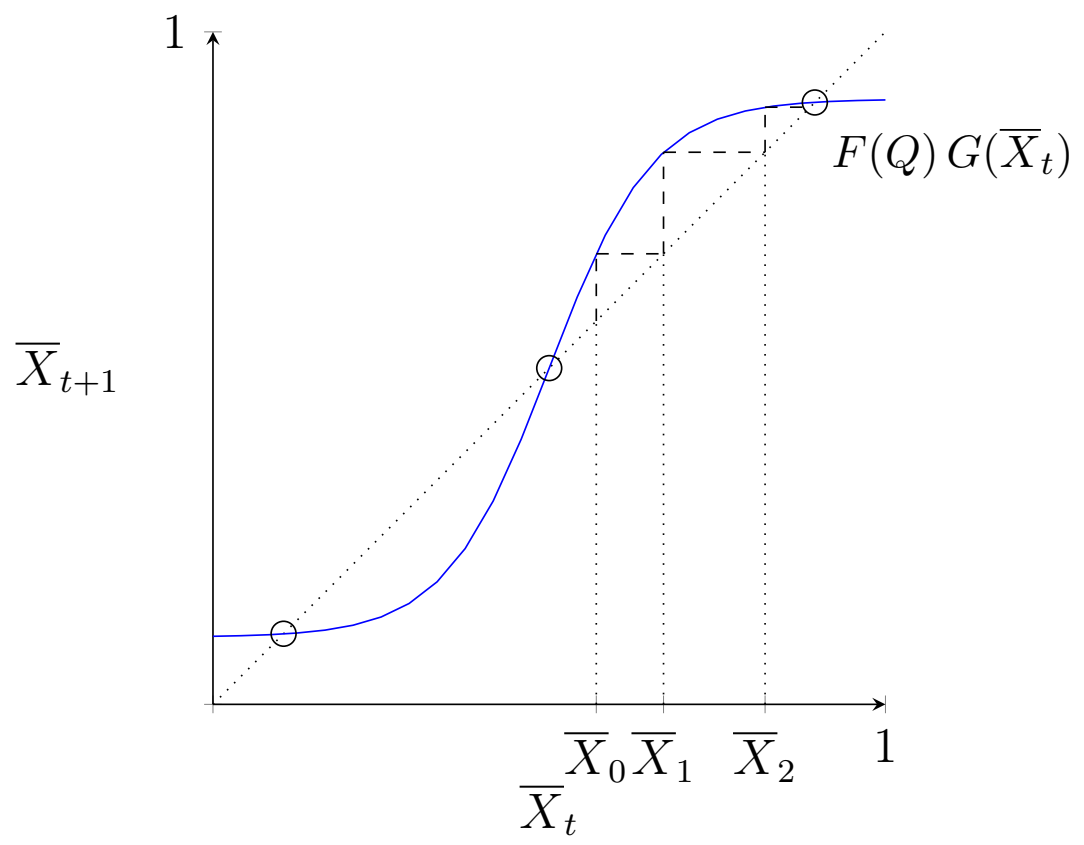

Figure 3: Steady state incorporation rates

This graph presents the dynamics of average incorporation decisions over time. An individual firm possess firm-specific thresholds in legal quality and average behavior, which are drawn from the c.d.f.s $F(\cdot)$ and $G(\cdot)$, respectively. A firm will incorporate in Delaware in time $t$ if Delaware's legal quality in time $t\left(Q_{t}\right)$ and the average decision of all other firms $\left(\bar{X}_{t-1}\right)$ exceed these thresholds. This graph assumes constant legal quality, $Q_{t}=Q$. The dotted line is the 45 degree line. Network effects, which obtain when $G(0)<1$, potentially induce multiple equilibria. 


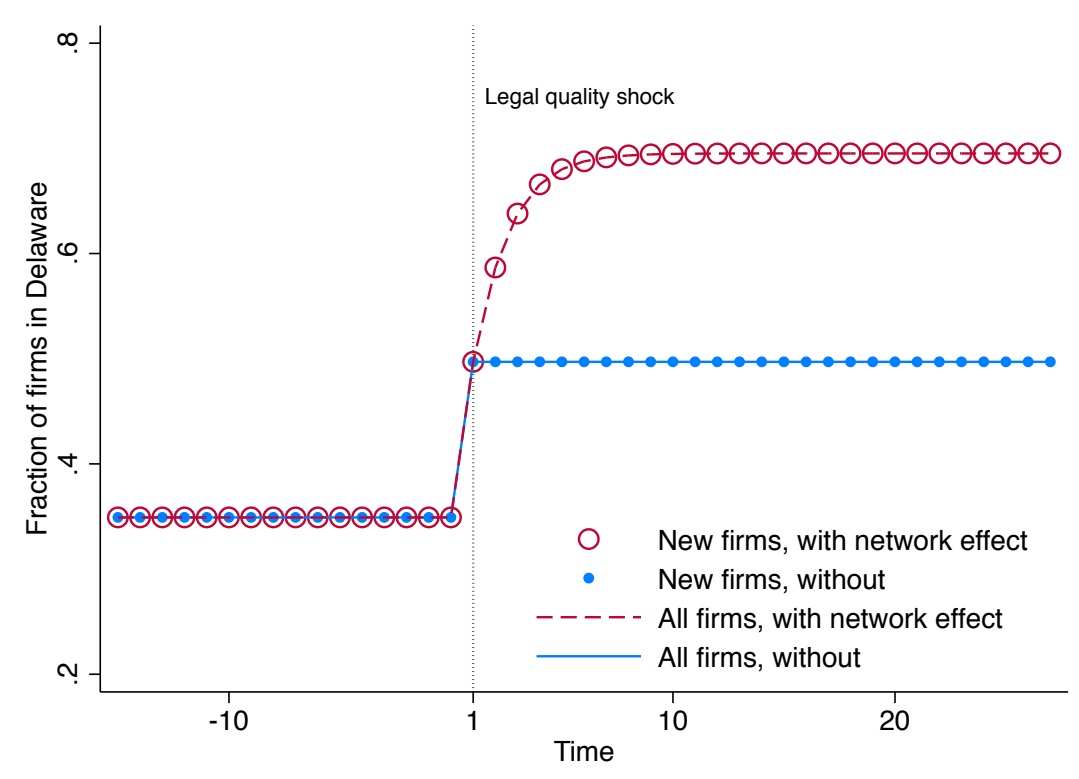

(a) Quality and network effects

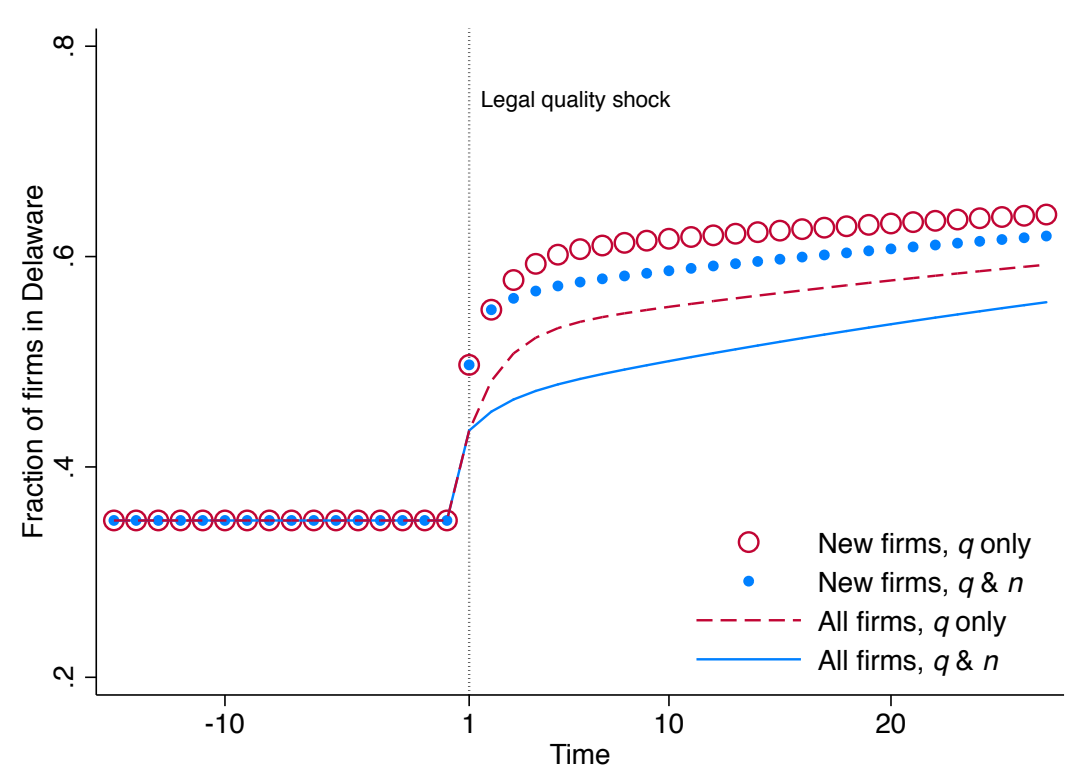

(b) State dependence in $q$ and $n$

Figure 4: Delaware share of firms in response to a one-time positive shock to legal quality This figure presents a simulation of the model developed in section 2 Panel $4 \mathrm{a}$ compares the responses of new and existing firms given quality and network effects (hollow circles and dashed line) to the responses given a quality effect only (solid circles and solid line). Panel $4 \mathrm{~b}$ presumes both quality and network effects; it compares responses given state dependence in the quality threshold only (hollow circles and dashed line) with responses given state dependence in both the quality and network thresholds (solid circles and solid line). The figures simulate the model using the following parameter values: $r=0.2, \delta=0.75, x \sim N(0, .6)$, $q \sim N(0.3,1), Q_{0}=.4, \Delta Q=1.1, b_{q}^{0}=0.75, b_{n}^{0}=0.11$. 


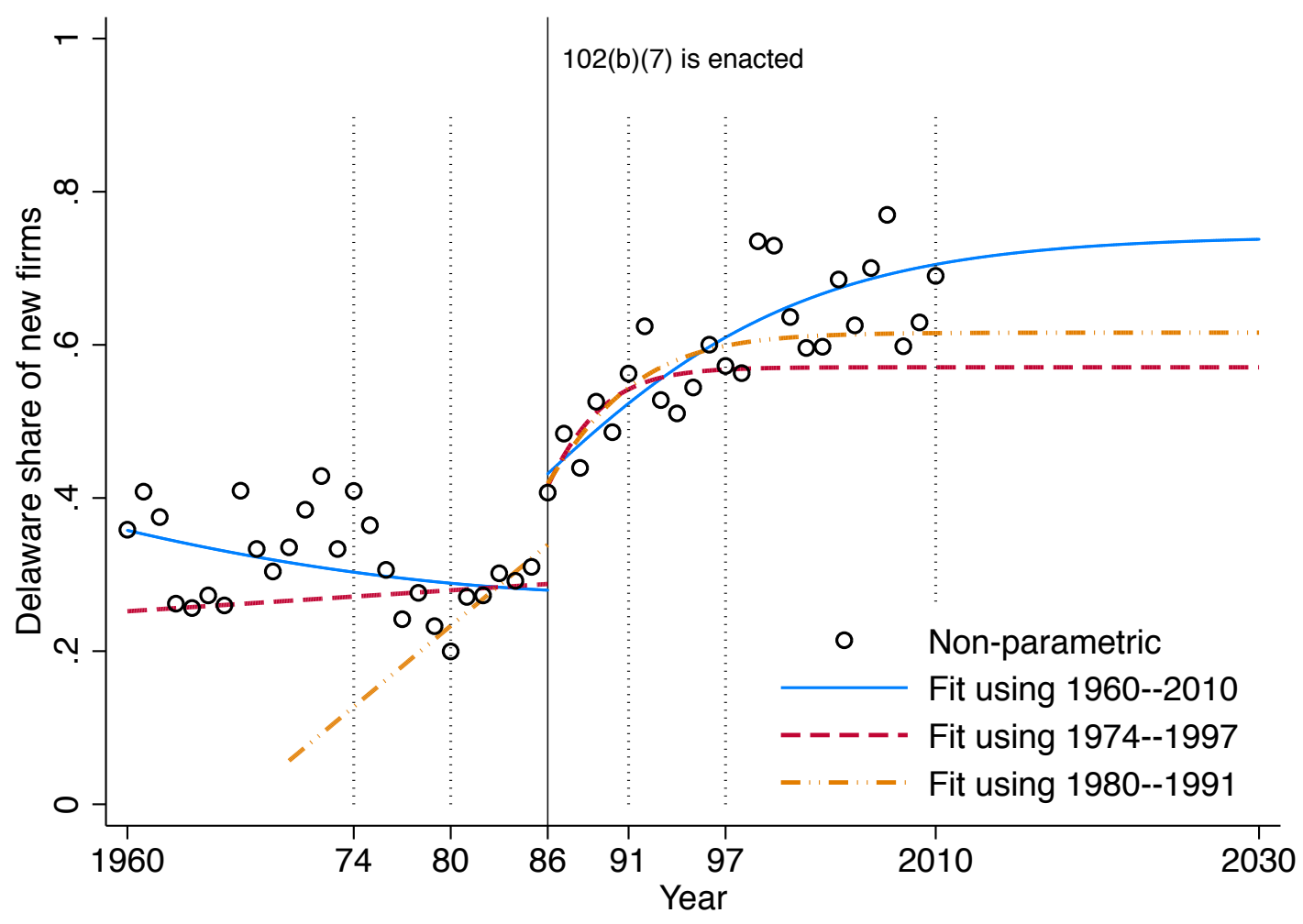

Figure 5: Delaware share of new corporations, parametric fits

Parametric fits of new firm shares correspond to specifications 3, 4, and 5 from table 2 


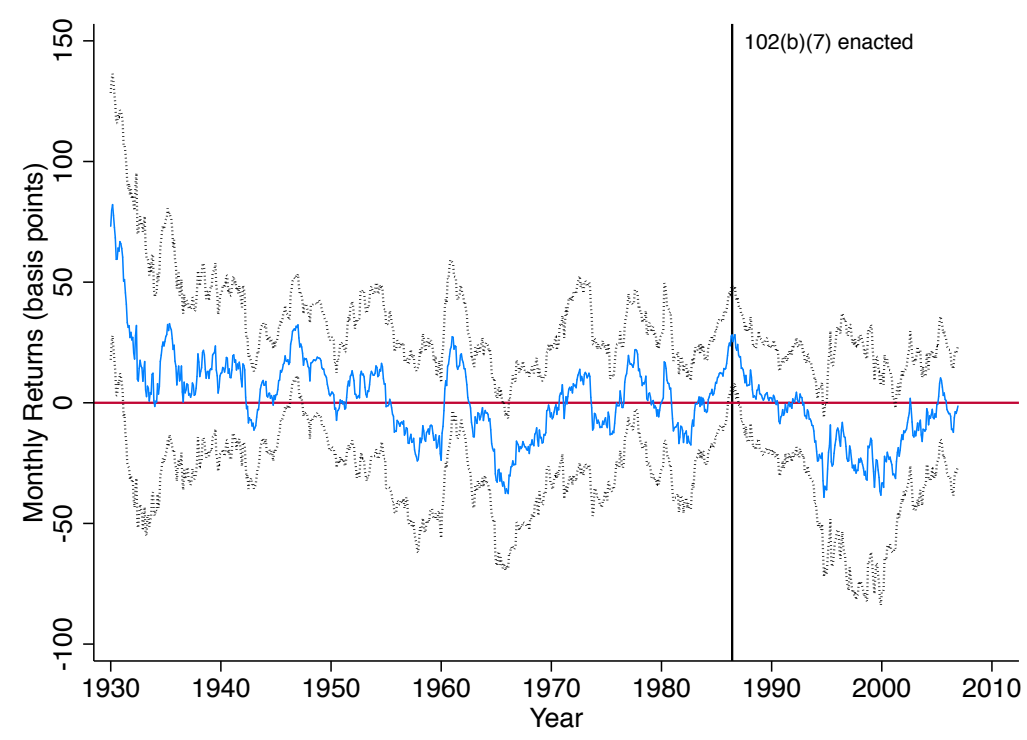

(a) Years 1930-2010

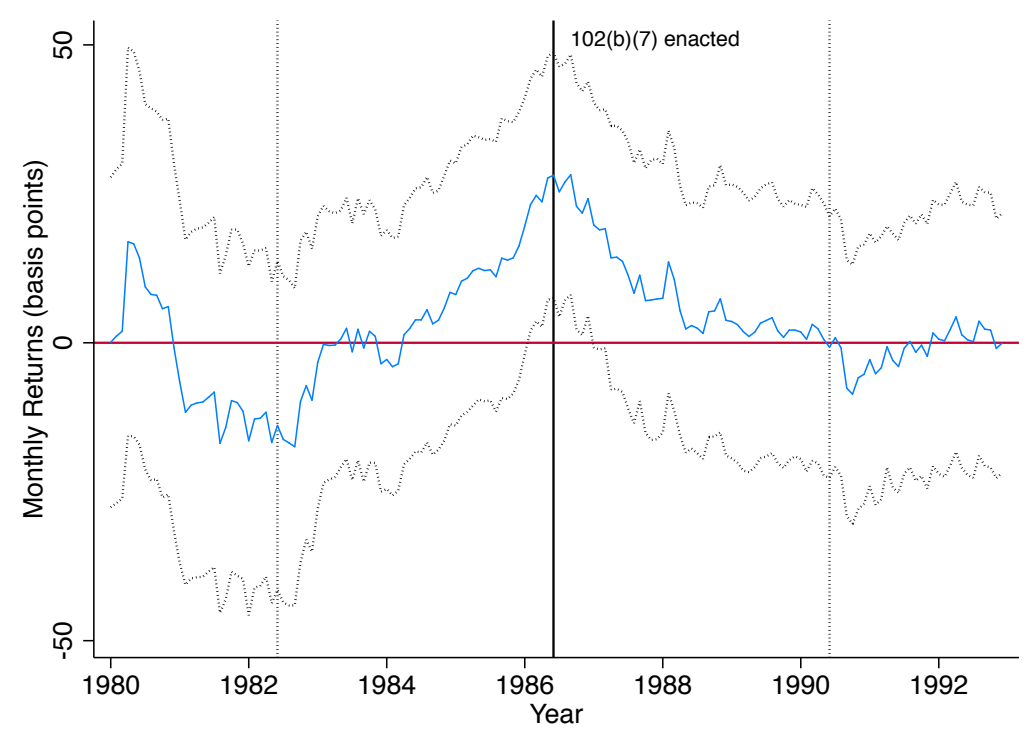

(b) Years 1980-1992

Figure 6: Abnormal returns of Delaware corporations (forwarding-looking moving average) The top panel graphs the four-factor-adjusted average monthly return of a zero-investment, value-weighted portfolio that buys Delaware firms and sells non-Delaware firms (solid line) and the 95 percent confidence interval (dotted lines). The bottom panel reproduces the top panel for the decade surrounding the passage of section 102(b)(7). Returns are calculated over a forward-looking 48-month moving window. Thus, the estimate at June 1986 (the month that the Delaware legislature passed section 102(b)(7)) covers the months June 1986 through May 1990. The four-factor adjustment estimates equation 21 by regressing the portfolio's returns on a constant and four controls for market exposure (MKTRF), firm size (SMB), book-to-market ratio (HML), and immediate past returns (UMD). The estimated abnormal return is the coefficient on the constant term ("alpha"). See Carhart (1997) and Fama and French (1993) for details on the construction of these controls. Stock price data come from CRSP. Corporate domicile data were hand-collected from several sources (see section 4). 


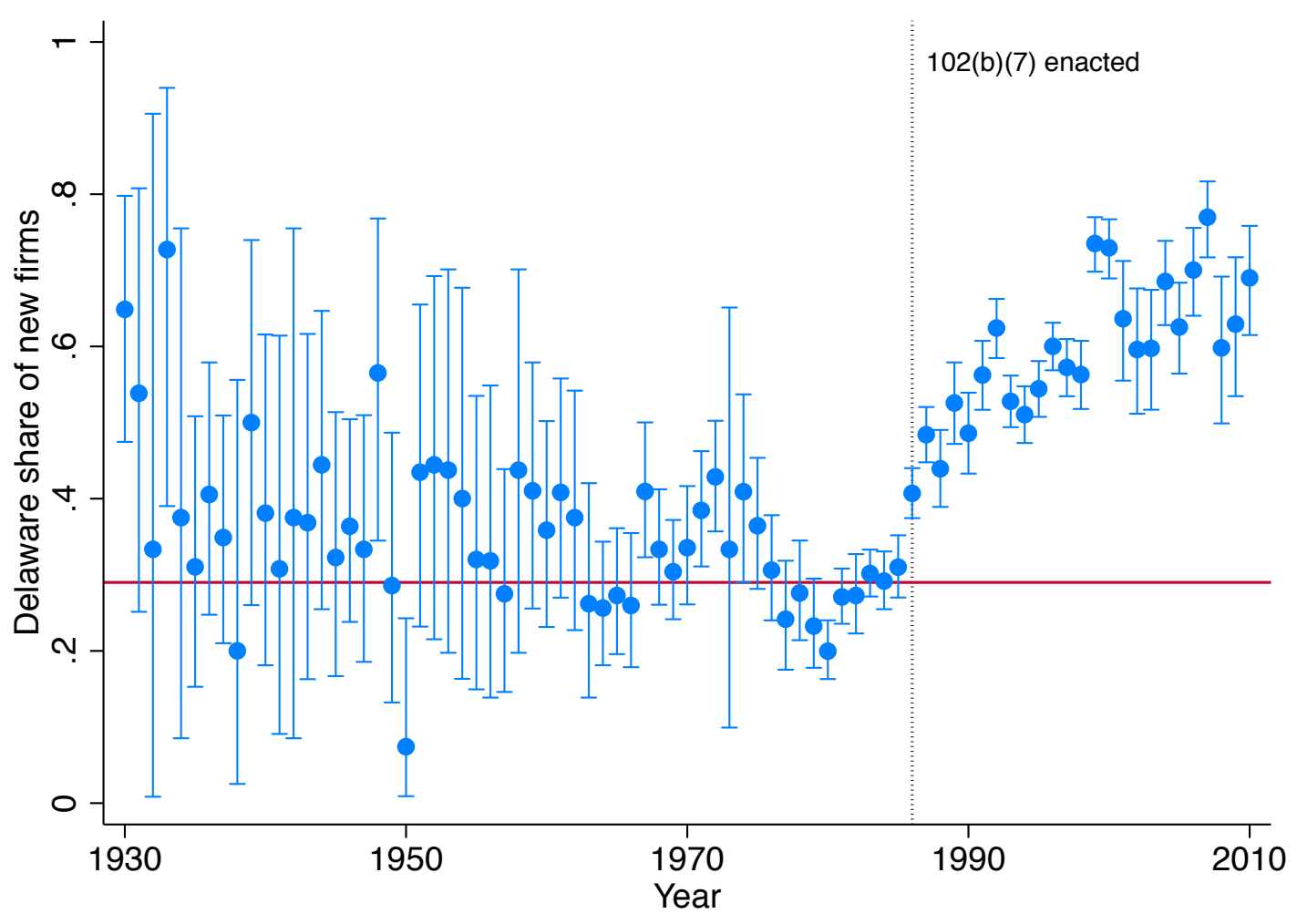

Figure 7: Delaware share of new corporations and 95 percent confidence intervals

The sample is all U.S.-domiciled public corporations listed on NYSE, AMEX, or NASDAQ. The identity of these corporations comes from the securities price data published by CRSP, which was expanded in 1963 to include AMEX and again in 1973 to include NASDAQ. A firm is defined as "new" during the calendar year of its initial public offering. The horizontal line is the estimate of the pre-shock steady state from table 2 . column 1. 
Table 1: Summary Statistics

\begin{tabular}{lrr}
\hline & Percent of firms & Number of firms \\
\cline { 3 - 3 } & & \\
State of incorporation & 0.50 & 11,230 \\
Delaware & 0.07 & 1,488 \\
California & 0.06 & 1,425 \\
New York & 0.03 & 665 \\
Nevada & 0.03 & 658 \\
Florida & & \\
Reincorporation & & \\
To Delaware & 0.06 & 1,401 \\
From Delaware & 0.01 & \\
& & \\
First primary exchange & & 2,684 \\
NYSE & 0.15 & 16,264 \\
AMEX & 0.12 & \\
NASDAQ & 0.73 & \\
\hline Years & $1930-2010$ & \\
Observations (firms) & 22,355 & \\
Observations (firm-years) & 272,948 &
\end{tabular}

Notes. The sample includes corporations whose first primary exchange was NYSE, AMEX, or NASDAQ. NYSE firms entered the sample in 1930, AMEX in 1963, and NASDAQ in 1973.

Source. Corporate domicile data were hand-collected from several sources (see section 4). 
Table 2: Network Effects in Corporate Governance

(1)

\section{Effects}

$\gamma \quad$ network effect

$\sigma \quad$ legal quality effect

$\gamma /(\gamma+\sigma)$
(2)

(3)

$(4)$

$(5)$

\begin{tabular}{|c|c|c|c|c|c|c|}
\hline$\gamma$ & network effect & $\begin{array}{c}1.05 \\
(0.21)\end{array}$ & $\begin{array}{c}1.13 \\
(0.23)\end{array}$ & $\begin{array}{c}1.11 \\
(0.23)\end{array}$ & $\begin{array}{c}0.54 \\
(0.09)\end{array}$ & $\begin{array}{c}0.58 \\
(0.65)\end{array}$ \\
\hline$\sigma$ & legal quality effect & $\begin{array}{c}0.45 \\
(0.08)\end{array}$ & $\begin{array}{c}0.57 \\
(0.11)\end{array}$ & $\begin{array}{c}0.54 \\
(0.12)\end{array}$ & $\begin{array}{c}0.44 \\
(0.09)\end{array}$ & $\begin{array}{c}0.24 \\
(0.07)\end{array}$ \\
\hline \multicolumn{2}{|c|}{$\gamma /(\gamma+\sigma)$} & $\begin{array}{c}0.70 \\
(0.05)\end{array}$ & $\begin{array}{c}0.66 \\
(0.06)\end{array}$ & $\begin{array}{c}0.67 \\
(0.06)\end{array}$ & $\begin{array}{c}0.55 \\
(0.06)\end{array}$ & $\begin{array}{c}0.71 \\
(0.24)\end{array}$ \\
\hline \multicolumn{7}{|c|}{ Delaware shares } \\
\hline $\bar{X}_{0}$ & initial steady state & $\begin{array}{c}0.30 \\
(0.01)\end{array}$ & $\begin{array}{c}0.28 \\
(0.01)\end{array}$ & $\begin{array}{c}0.28 \\
(0.01)\end{array}$ & $\begin{array}{c}0.29 \\
(0.01)\end{array}$ & $\begin{array}{c}0.32 \\
(0.01)\end{array}$ \\
\hline $\bar{X}_{\cdot 11}$ & immediate response & $\begin{array}{c}0.43 \\
(0.02)\end{array}$ & $\begin{array}{c}0.43 \\
(0.02)\end{array}$ & $\begin{array}{c}0.43 \\
(0.02)\end{array}$ & $\begin{array}{c}0.42 \\
(0.01)\end{array}$ & $\begin{array}{c}0.42 \\
(0.01)\end{array}$ \\
\hline $\bar{X}^{*}$ & new steady state & $\begin{array}{c}0.74 \\
(0.07) \\
\end{array}$ & $\begin{array}{c}0.74 \\
(0.07) \\
\end{array}$ & $\begin{array}{c}0.74 \\
(0.07) \\
\end{array}$ & $\begin{array}{c}0.57 \\
(0.02) \\
\end{array}$ & $\begin{array}{c}0.62 \\
(0.22) \\
\end{array}$ \\
\hline \multirow{3}{*}{\multicolumn{2}{|c|}{$\begin{array}{l}\text { Pre-shock trend } \\
\text { Years } \\
\text { Observations }\end{array}$}} & Constant & Linear & Quadratic & Linear & Linear \\
\hline & & $1960-2010$ & $1960-2010$ & $1960-2010$ & 1974-1997 & 1980-1991 \\
\hline & & 17,166 & 17,166 & 17,166 & 12,045 & 6,518 \\
\hline
\end{tabular}

Notes. This table presents estimates of quality and network effects in incorporation decisions. The estimates come from fitting new firms' incorporation decisions to equation 15 using nonlinear least squares and the delta method for inference. Each column presents estimates obtained using different time windows and pre-shock time-trends. Network and quality effects, $\gamma$ and $\sigma$, respectively, are formally defined in section 3 . $\gamma /(\gamma+\sigma)$ is the relative contribution of network effects to incorporation decisions.

Sources. Corporate domicile data were hand-collected from several sources (see section 4 . 
Table 3: State Dependence in Corporate Governance

\begin{tabular}{|c|c|c|c|c|c|c|}
\hline & & (1) & $(2)$ & $(3)$ & (4) & $(5)$ \\
\hline \multicolumn{7}{|c|}{ State dependence } \\
\hline$\beta$ & unbiased estimate & $\begin{array}{c}0.80 \\
(0.03)\end{array}$ & $\begin{array}{c}0.81 \\
(0.03)\end{array}$ & $\begin{array}{c}0.81 \\
(0.03)\end{array}$ & $\begin{array}{c}0.80 \\
(0.01)\end{array}$ & $\begin{array}{c}0.80 \\
(0.02)\end{array}$ \\
\hline$\beta-\xi$ & lower bound & $\begin{array}{c}0.67 \\
(0.03)\end{array}$ & $\begin{array}{c}0.70 \\
(0.03)\end{array}$ & $\begin{array}{c}0.70 \\
(0.03)\end{array}$ & $\begin{array}{c}0.70 \\
(0.02)\end{array}$ & $\begin{array}{c}0.67 \\
(0.00)\end{array}$ \\
\hline \multicolumn{7}{|c|}{ Reincorporation probabilities } \\
\hline$p_{0}$ & initial steady state & $\begin{array}{c}0.007 \\
(0.001)\end{array}$ & $\begin{array}{c}0.007 \\
(0.001)\end{array}$ & $\begin{array}{c}0.007 \\
(0.001)\end{array}$ & $\begin{array}{c}0.006 \\
(0.001)\end{array}$ & $\begin{array}{c}0.008 \\
(0.001)\end{array}$ \\
\hline$p_{1}$ & immediate response & $\begin{array}{c}0.025 \\
(0.000)\end{array}$ & $\begin{array}{c}0.025 \\
(0.000)\end{array}$ & $\begin{array}{c}0.025 \\
(0.000)\end{array}$ & $\begin{array}{c}0.025 \\
(0.000)\end{array}$ & $\begin{array}{c}0.025 \\
(0.000)\end{array}$ \\
\hline$p^{*}$ & new steady state & $\begin{array}{c}0.018 \\
(0.004)\end{array}$ & $\begin{array}{c}0.018 \\
(0.004)\end{array}$ & $\begin{array}{c}0.018 \\
(0.004)\end{array}$ & $\begin{array}{c}0.012 \\
(0.002)\end{array}$ & $\begin{array}{c}0.021 \\
(0.003)\end{array}$ \\
\hline \multicolumn{7}{|c|}{ Delaware shares } \\
\hline $\bar{X}_{0}$ & initial steady state & $\begin{array}{c}0.31 \\
(0.02)\end{array}$ & $\begin{array}{c}0.29 \\
(0.02)\end{array}$ & $\begin{array}{c}0.29 \\
(0.02)\end{array}$ & $\begin{array}{c}0.29 \\
(0.02)\end{array}$ & $\begin{array}{c}0.31 \\
(0.00)\end{array}$ \\
\hline $\bar{X}_{\cdot 11}$ & immediate response & $\begin{array}{c}0.47 \\
(0.01)\end{array}$ & $\begin{array}{c}0.47 \\
(0.01)\end{array}$ & $\begin{array}{c}0.47 \\
(0.01)\end{array}$ & $\begin{array}{c}0.48 \\
(0.00)\end{array}$ & $\begin{array}{c}0.48 \\
(0.00)\end{array}$ \\
\hline $\bar{X}^{*}$ & new steady state & $\begin{array}{c}0.78 \\
(0.07) \\
\end{array}$ & $\begin{array}{c}0.78 \\
(0.07) \\
\end{array}$ & $\begin{array}{c}0.78 \\
(0.07) \\
\end{array}$ & $\begin{array}{c}0.61 \\
(0.02) \\
\end{array}$ & $\begin{array}{c}0.89 \\
(0.00) \\
\end{array}$ \\
\hline Pre-sl & ock trend & Constant & Linear & Quadratic & Linear & Linear \\
\hline Years & & $1960-2010$ & $1960-2010$ & 1960-2010 & 1974-1997 & 1980-1991 \\
\hline Obser & rations (eq 15 ) & 17,205 & 17,205 & 17,205 & 12,045 & 6,518 \\
\hline Obser & ations (eq $\overline{20}$ & 50,422 & 50,422 & 50,422 & 30,996 & 16,505 \\
\hline
\end{tabular}

Notes. This table presents estimates of barriers to reincorporation, modeled in section 2 as state dependence in incorporation decisions. Each column lists the coefficients obtained from jointly estimating equations 15 and 20 using nonlinear least squares and the delta method for inference. The data have been coarsened as described in section 5.2 . The measure of state dependence, $\beta$, is formally defined in equation 14 and is interpreted as the fraction of the initial growth in Delaware's share of firms that was forgone on account of barriers to reincorporation. $\xi$ (equation 12 is a positive remainder term that accounts for changes in the baseline rate of reincorporations (i.e, those driven by random, firm-specific shocks). An unbiased estimate of $\beta$ incorporates this remainder term. $\beta-\xi$ is thus the lower bound measure of state dependence that ignores changes in the baseline rate of reincorporations. Reincorporation probabilities are the annual hazard of a non-Delaware corporation reincorporating to Delaware before, immediately after, and in the long run after the passage of $102(\mathrm{~b})(7)\left(p_{0}, p_{1}\right.$, and $p^{*}$, respectively).

Source. Corporate domicile data were hand-collected from several sources (see section 4 . 
Table 4: Monthly Abnormal Returns of Delaware minus Non-Delaware Portfolio

\begin{tabular}{|c|c|c|c|c|c|c|c|c|}
\hline \multirow[b]{4}{*}{ All } & \multirow[b]{3}{*}{$\alpha$} & & & & & \multicolumn{3}{|c|}{ Portfolio composition } \\
\hline & & \multicolumn{4}{|c|}{ Risk factors } & \multicolumn{2}{|c|}{ \# Firms } & \multirow{2}{*}{$\frac{\text { Mktcap }}{\text { Del. share }}$} \\
\hline & & MKTRF & SMB & HML & $\mathrm{UMD}$ & Del. & Non-Del. & \\
\hline & $\begin{array}{l}0.28^{*} \\
(0.11)\end{array}$ & $\begin{array}{c}0.10^{* *} \\
(0.02)\end{array}$ & $\begin{array}{l}0.18^{* *} \\
(0.04)\end{array}$ & $\begin{array}{l}-0.00 \\
(0.06)\end{array}$ & $\begin{array}{c}0.06 \\
(0.04)\end{array}$ & 2,367 & 3,637 & 0.47 \\
\hline Large Cap & $\begin{array}{l}0.31^{*} \\
(0.12)\end{array}$ & $\begin{array}{c}0.10^{* *} \\
(0.03)\end{array}$ & $\begin{array}{c}0.21^{* *} \\
(0.05)\end{array}$ & $\begin{array}{l}-0.00 \\
(0.06)\end{array}$ & $\begin{array}{c}0.06 \\
(0.05)\end{array}$ & 288 & 313 & 0.48 \\
\hline Small Cap & $\begin{array}{c}0.13 \\
(0.10)\end{array}$ & $\begin{array}{c}0.13^{* *} \\
(0.02)\end{array}$ & $\begin{array}{l}0.21^{* *} \\
(0.04)\end{array}$ & $\begin{array}{l}-0.02 \\
(0.05)\end{array}$ & $\begin{array}{c}0.06 \\
(0.04)\end{array}$ & 2,079 & 3,324 & 0.43 \\
\hline Est. before 1985 & $\begin{array}{l}0.26^{*} \\
(0.11)\end{array}$ & $\begin{array}{c}0.10^{* *} \\
(0.02)\end{array}$ & $\begin{array}{c}0.16^{* *} \\
(0.04)\end{array}$ & $\begin{array}{c}0.01 \\
(0.06)\end{array}$ & $\begin{array}{c}0.06 \\
(0.04)\end{array}$ & 1,569 & 2,500 & 0.46 \\
\hline Reincorporations exluded & $\begin{array}{l}0.27^{*} \\
(0.10)\end{array}$ & $\begin{array}{c}0.10^{* *} \\
(0.02)\end{array}$ & $\begin{array}{l}0.16^{* *} \\
(0.04)\end{array}$ & $\begin{array}{c}0.01 \\
(0.06)\end{array}$ & $\begin{array}{c}0.06 \\
(0.04)\end{array}$ & 2,105 & 3,637 & 0.46 \\
\hline Reincorp. exluded \& Est. before 1985 & $\begin{array}{l}0.25^{*} \\
(0.11)\end{array}$ & $\begin{array}{l}0.09^{* *} \\
(0.02)\end{array}$ & $\begin{array}{l}0.14^{* *} \\
(0.04)\end{array}$ & $\begin{array}{c}0.02 \\
(0.06)\end{array}$ & $\begin{array}{c}0.06 \\
(0.04)\end{array}$ & 1,391 & 2,500 & 0.45 \\
\hline All & $\begin{array}{c}0.26 \\
(0.15)\end{array}$ & & & & & 2,367 & 3,637 & 0.47 \\
\hline Large Cap & $\begin{array}{c}0.27 \\
(0.16)\end{array}$ & & & & & 288 & 313 & 0.48 \\
\hline
\end{tabular}

Notes. This table estimates abnormal returns of Delaware versus non-Delaware firms. I construct portfolios and regress the returns on four controls for market exposure (MKTRF), firm size (SMB), book-to-market ratio (HML), and immediate past returns (UMD). I interpret the constant term, $\alpha$, as the abnormal return of the portfolio. See Carhart (1997) and Fama and French (1993) for details on the construction of these controls. The time period for all portfolios is the first 48 months after the Delaware legislature passed section 102(b)(7) (June 1986 - May 1990). Each row is a zero-investment, value-weighted portfolio that buys Delaware firms and sells short non-Delaware firms. "All corporations" sells all non-Delaware corporations and buys all non-Delaware corporations; "Large cap" only buys and sells firms in the top decile of market capitalization each month; "Est. before 1985" only buys and sells firms that were established before January 1, 1985; "Reincorporations excluded" sells non-Delaware firms and buys Delaware firms only if they did not reincorporate to Delaware after June 1986. "Del. firms" is the average number of Delaware firms in the portfolio each month and non-Del. is the average number of non-Delaware firms. "Del. share" is the market capitalization of Delaware firms in the portfolio as a share of the market capitalization of all firms in the portfolio. * indicates statistically significantly different from zero at 95 percent confidence. ${ }^{* *}$ indicates statistically significantly different from zero at 99 percent confidence.

Source. Stock price data come from CRSP. Corporate domicile data were hand-collected from several sources (see section 4 . 
Table 5: Monthly Abnormal Returns of Portfolios that Exclude Delaware Firms

\begin{tabular}{|c|c|c|c|c|c|c|c|c|}
\hline & \multirow[b]{3}{*}{$\alpha$} & & & & & \multicolumn{3}{|c|}{ Portfolio composition } \\
\hline & & \multicolumn{4}{|c|}{ Risk factors } & \multicolumn{2}{|c|}{ \# Firms } & \multirow{2}{*}{$\frac{\text { Mktcap }}{\text { Buy share }}$} \\
\hline & & MKTRF & SMB & HML & UMD & Buy & Sell & \\
\hline Limited liability (LL) states vs non-LL states & $\begin{array}{c}0.02 \\
(0.19)\end{array}$ & $\begin{array}{l}0.09^{*} \\
(0.04)\end{array}$ & $\begin{array}{c}-0.18^{*} \\
(0.08)\end{array}$ & $\begin{array}{c}0.02 \\
(0.10)\end{array}$ & $\begin{array}{l}-0.02 \\
(0.07)\end{array}$ & 2,328 & 1,299 & 0.69 \\
\hline Poison pill $(\mathrm{PP})$ states vs non-PP states & $\begin{array}{c}0.07 \\
(0.23)\end{array}$ & $\begin{array}{c}0.05 \\
(0.05)\end{array}$ & $\begin{array}{c}0.02 \\
(0.09)\end{array}$ & $\begin{array}{c}0.15 \\
(0.12)\end{array}$ & $\begin{array}{c}0.05 \\
(0.09)\end{array}$ & 708 & 3,064 & 0.23 \\
\hline States with LL \& PP vs states with neither & $\begin{array}{c}0.02 \\
(0.24)\end{array}$ & $\begin{array}{c}0.09 \\
(0.05)\end{array}$ & $\begin{array}{l}-0.10 \\
(0.10)\end{array}$ & $\begin{array}{c}0.11 \\
(0.13)\end{array}$ & $\begin{array}{c}0.05 \\
(0.09)\end{array}$ & 673 & 1,751 & 0.45 \\
\hline
\end{tabular}

Notes. This table estimates abnormal returns of zero-investment portfolios that are long on some states and short on others. Delaware companies are excluded from all portfolios. I regress the returns of these portfolios on four controls for market exposure (MKTRF), firm size (SMB), book-to-market ratio (HML), and immediate past returns (UMD). I interpret the constant term, $\alpha$, as the abnormal return of the portfolio. See Carhart (1997) and Fama and French (1993) for details on the construction of these controls. The first portfolio ("Limited liability (LL) vs non-LL states") buys firms incorporated in states that have passed a limited liability statute and sells short firms incorporated in states without a limited liability statute. A state exits the buy-side of this portfolio in the month before the enactment of the statute and enters the sell-side in the month following enactment. The second portfolio ("Poison pill (PP) vs non-PP states") is similarly defined. It buys firms incorporated in states that have affirmed the poison pill and sells short all others. The final row ("States with LL \& PP vs states with neither") buys firms in states with both limited liability and poison pills, and sells firms in states that have neither limited liability nor poison pills. The time period of the first portfolio is the first 48 months after the Delaware legislature passed its own limited liability statute, codified in section 102(b)(7) (June 1986 - May 1990). The time period of the second and third portfolios is the first 48 months after the Delaware Supreme Court affirmed the poison pill in Moran (November 1985 - October 1989). "\# Firms - Buy" is the average number of firms in on the buy side of the portfolio each month and "Sell" is the average on the sell side. "Buy share" is the market capitalization of Buy firms in the portfolio as a share of the market capitalization of all firms in the portfolio. ${ }^{*}$ indicates statistically significantly different from zero at 95 percent confidence. ${ }^{* *}$ indicates statistically significantly different from zero at 99 percent confidence.

Source. Stock price data come from CRSP. Corporate domicile data were hand-collected from several sources (see section 4 . 